\title{
Transcriptome Analysis of Arabidopsis Clubroots Indicate a Key Role for Cytokinins in Disease Development
}

\author{
Johannes Siemens, ${ }^{1}$ Ingo Keller, ${ }^{2,4}$ Johannes Sarx, ${ }^{1}$ Sabine Kunz, ${ }^{1}$ Astrid Schuller, ${ }^{1}$ Wolfgang Nagel, ${ }^{2}$ \\ Thomas Schmülling, ${ }^{3}$ Martin Parniske, ${ }^{4}$ and Jutta Ludwig-Müller ${ }^{1}$ \\ ${ }^{1}$ Institut für Botanik and ${ }^{2}$ Zentrum für Hochleistungsrechnen, Technische Universität Dresden, 01062 Dresden, Germany; \\ ${ }^{3}$ Institut für Biologie - Angewandte Genetik, Freie Universität Berlin, Albrecht-Thaer-Weg 6, 14195 Berlin, Germany; \\ ${ }^{4}$ Department Biologie I, Bereich Genetik, Ludwig-Maximilians-Universität, Maria-Ward-Str. 1a, 80638 München, Germany
}

Submitted 16 August 2005. Accepted 2 January 2006.

\begin{abstract}
The clubroot disease of the family Brassicaceae is caused by the obligate biotrophic protist Plasmodiophora brassicae. Infected roots undergo a developmental switch that results in the formation of aberrant roots (clubs). To investigate host gene expression during the development of the disease, we have used the Arabidopsis ATH1 genome array. Two timepoints were chosen, an early timepoint at which the pathogen has colonized the root but has induced only very limited change of host cell and root morphology and a later timepoint at which more than $60 \%$ of the host root cells were colonized and root morphology was drastically altered. At both timepoints, more than 1,000 genes were differentially expressed in infected versus control roots. These included genes associated with growth and cell cycle, sugar phosphate metabolism, and defense. The involvement of plant hormones in club development was further supported; genes involved in auxin homeostasis, such as nitrilases and members of the $\mathrm{GH} 3$ family, were upregulated, whereas genes involved in cytokinin homeostasis (cytokinin synthases and cytokinin oxidases/dehydrogenases) were already strongly downregulated at the early timepoint. Cytokinin oxidase/dehydrogenase overexpressing lines were disease resistant, clearly indicating the importance of cytokinin as a key factor in clubroot disease development.
\end{abstract}

Additional keywords: disease resistance, root gall.

The clubroot disease of the family Brassicaceae, caused by the obligate biotroph Plasmodiophora brassicae, is one of the most damaging diseases within this plant family and is difficult to control by either chemical or cultural means (Crisp et al. 1989). The growth of clubroot-infected plants is stunted compared with healthy plants, and the root system shows typical gall formation. Cross-sections of infected roots show that the galls are caused by cell elongation and cell division (Kobelt et al. 2000; Mithen and Magrath 1992). The life cycle of the obligate pathogen consists of two phases, the primary phase, which is restricted to root hairs of the infected plant, and the secondary phase, which occurs in the cortex and stele

Corresponding author: J. Ludwig-Müller; Telephone: +49 (0351) 46333939; Fax: +49 (0351) 46337032; E-mail: Jutta.Ludwig-Mueller@tu-dresden.de

* The $\boldsymbol{e}$-Xtra logo stands for "electronic extra" and indicates the HTML abstract available on-line contains three supplemental tables not included in the print edition. of hypocotyl and roots (Ingram and Tommerup 1972). During the secondary phase, plasmodia are developing that later sporulate and form resting spores (Braselton 1995; LudwigMüller 1999).

The developing clubs form a strong metabolic sink on the host, although under optimal growth conditions, the host may tolerate club growth during early growth phases without reduction of shoot growth (Rausch et al. 1981). It was shown that plant hormones, in particular auxins and cytokinins, are correlated with the development of root galls (Butcher et al. 1974; Dekhuijzen and Overeem 1971). The increase of indole 3-acetic acid (IAA) might be due to the increased synthesis and turnover of putative host auxin precursors indole-3-acetaldoxime, indole-3-methylglucosinolate, and indole-3-acetonitrile in infected roots (Butcher et al. 1984; Grsic et al. 1999; GrsicRausch et al. 2000; Rausch et al. 1981, 1983; Searle et al. 1982).

In addition to auxin, increased concentrations of free and bound cytokinins were found (Dekhuijzen 1981; Dekhuijzen and Overeem 1971). Dekhuijzen (1981) also showed that the contents of bound and free cytokinins are different in the host cytoplasm and plasmodia of the pathogen. Müller and Hilgenberg (1986) isolated young secondary plasmodia and showed that they were able to incorporate ${ }^{14} \mathrm{C}$-adenine into trans-zeatin. It was thus assumed that the increase in cytokinins is at least partly derived from active synthesis of zeatin by plasmodia of $P$. brassicae. Due to the small amount of detectable cytokinin production, it was unclear whether this constituted an important pathogenicity factor (Müller and Hilgenberg 1986).

The morphological description of the disease in A. thaliana revealed two overlapping processes in the root cortex during the development of the club. At the beginning of club growth, cell division is the predominant process, whereas cell enlargement dominated the later developmental stages (Kobelt et al. 2000). This correlates with cytokinin production by the vegetative plasmodia of the pathogen during earlier disease stages (Dekhuijzen 1981) and increased levels of auxin during later disease stages, when plasmodia were forming sporangia and resting spores (Grsic-Rausch et al. 2000). Club growth might be an overall result of the ratios of these two classes of hormones during the disease, whereas cytokinin dominated the earlier and auxin the later phase.

To understand disease development on the molecular level, several approaches were followed to isolate genes differentially expressed during gall formation. RNA fingerprinting with arbitrary primed polymerase chain reaction (PCR) (Ito et 
al. 1999), a random priming approach to isolate cDNAs (Schuller and Ludwig-Müller 2002), and subtractive cDNA libraries (Arbeiter et al. 2002; Graf et al. 2004) were used to isolate gene fragments that could be related to the development of a club. However, all these studies revealed a mixture of plant and protist genes, and so far, only one unknown gene from the protist has shown correlation to pathogenesis (Ito et al. 1999).

In order to overcome these limitations in the molecular analysis of clubroot in this study, host gene expression was monitored during the development of the disease (10 and 23 days after inoculation [dai]), using the Arabidopsis ATH1 genome array. The transcriptome analysis has further elucidated the role of cytokinin regulation during clubroot development and has refined the decisive steps in establishing a strong metabolic sink in the root tissue by the pathogen. Moreover, we demonstrate a resistance phenotype to clubroot of cytokinindeficient $A t C K X$-overexpressing plants.

\section{RESULTS}

\section{Gene expression during clubroot development.}

Two distinct developmental stages of clubroot disease were analyzed by gene expression profiling. At the early timepoint, no disease symptoms were visible and the pathogen was mostly at the stage of young vegetative plasmodia (Fig. 1B). The cell size was almost comparable to that of control roots (Fig. 1A). The second timepoint was characterized by clearly visible clubs and, in root sections, plasmodia, sporangia, and resting spores of the pathogen could be found (Fig. 1C). Between 1,000 and 2,000 genes were differentially expressed at each timepoint of 14,000 expressed genes at one of the analyzed timepoints in infected or control roots. The complete data set is available at ArrayExpress of the European Bioinformatics Institute, experiment number E-MEXP-254. About 1,500 and 1,900 genes were upregulated at timepoint 1 (TP1) and timepoint 2 (TP2), respectively, whereas approximately 1,400 and 2,000 genes were downregulated at the two timepoints. The same 483 genes were upregulated at TP1 and TP2, and 705 genes were similarly downregulated at the two timepoints ( $>2$ fold change).

Grouping the differentially expressed genes according to their GO annotation on The Arabidopsis Information Resource (TAIR) website revealed few obvious categories. Mitochondrial-associated transcripts were upregulated at TP1 and chloroplast-associated genes at TP2. The latter is due to the fact that infected hypocotyls of older plants, which are found above ground, are green.

Major metabolic pathways (Fig. 2) and transport components (Fig. 3) were analyzed using MAPMAN software (Thimm et al. 2004). The visual display of MAPMAN-generated data organizes genes in contextual groups, which facilitates the discovery of general trends. In the current study, we used MAPMAN and compared control with infected roots for each timepoint to visualize gene expression data for complex processes. Visualization of metabolism resulted in the observation that, at the first timepoint, only a few pathways seem to be differentially regulated (Fig. 2A), including starch and $S$-metabolism. At the second timepoint (Fig. 2B), the photosynthetic apparatus is dramatically induced (discussed above). In addition, starch, lipids, and secondary metabolism, especially flavonoids, seem to be upregulated. Second, we found many major transport processes differentially regulated between the two timepoints (Fig. 3). At TP1, not many transport processes seem to be regulated at all, while at the second timepoint, several are increased, including sugars, lipids, ions, and other nutrients $(\mathrm{N}, \mathrm{S}, \mathrm{P})$. This indicates high reserveaccumulation during TP2 in infected roots.
Comparing highly expressed genes at TP1 with those at TP2 in infected roots only supports those findings (Table 1). The genes induced more than 20-fold from infected roots at TP2 included many genes associated with reserve accumulation (e.g., lipid transfer proteins, starch synthesis) but also dehydrins/ LEA proteins, which may indicate the stress situation of the infected roots at later timepoints. On the other hand, strongly downregulated genes in infected roots at TP2 compared with TP1 (Table 2) included many defense-related proteins (discussed below).

For more detailed analysis, we have chosen genes most likely involved in i) defense related genes, ii) cell division end elongation, and iii) hormone metabolism and perception (auxins and cytokinins) (Tables 3 and 4).

Consistent with the observation that $P$. brassicae can live inside its host for a long period without affecting vitality, the majority of annotated resistance and defense genes were not differentially expressed in clubs. This has been summarized for biotrophic pathogens as a hallmark in the interaction with plants (Panstruga 2003). Although a few defense genes were highly upregulated, a greater number of defense- and resistancerelated genes were downregulated during the interaction. Of 312 genes identified as defense and disease-resistance related only $5 \%$ were upregulated at the first timepoint and $7 \%$ at the second timepoint. On the contrary, at the first timepoint, about $7 \%$ were downregulated and, at the second timepoint, this number doubled to $14 \%$.

Several genes involved in growth and cell cycle control were strongly induced. Several cyclins were upregulated at the first timepoint, and two members of the alpha-expansin gene family were highly induced at the second infection timepoint. During later timepoints of pathogenesis, cell elongation is taking place, whereas cell division can be found mostly at earlier timepoints. Concomitantly, we found that cell cycle genes were upregulated during the earlier timepoint.
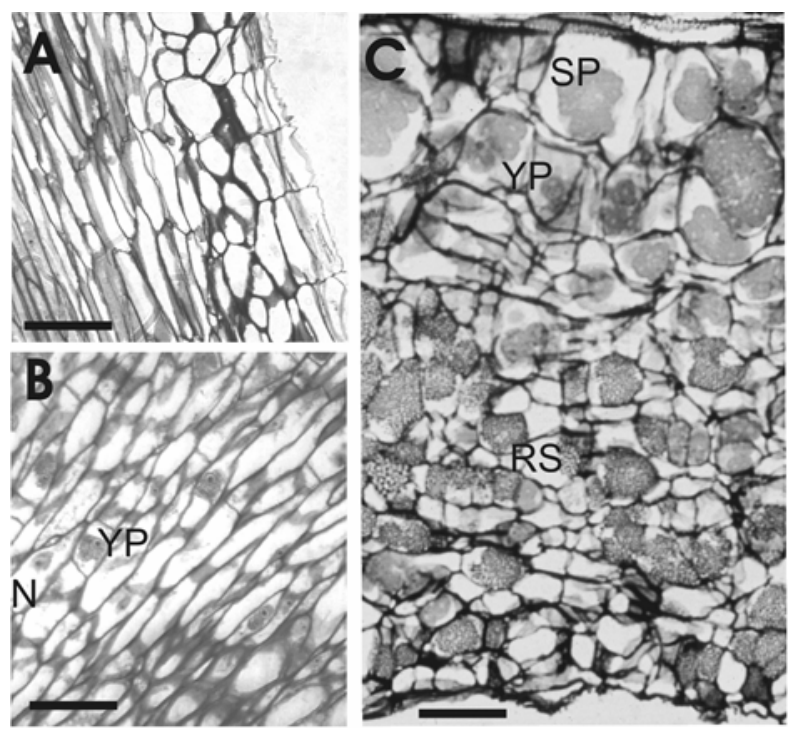

Fig. 1. Longitudinal sections of Arabidopsis control roots and roots infected with Plasmodiphora brassicae at the two timepoints chosen for the microarray experiment. A, Arabidopsis control roots. B, Root cortex at timepoint 1 (10 days after inoculation). C, Middle of a club at timepoint 2 (23 days after inoculation). Bars represent $50 \mu \mathrm{m}$. In B, typical young plasmodia are visible (YP) surrounding, in some cases, the host nucleus $(\mathrm{N})$, which is also stained by methylene blue and basic fuchsin. In $\mathrm{C}$, young plasmodia (YP), large secondary plasmodia (SP), and cells filled with resting spores (RS) can be seen. The plasmodia are more often found in the inner root cortex, whereas resting spores are more frequently found in the outer parts of the root. 


\section{Metabolism Overview}
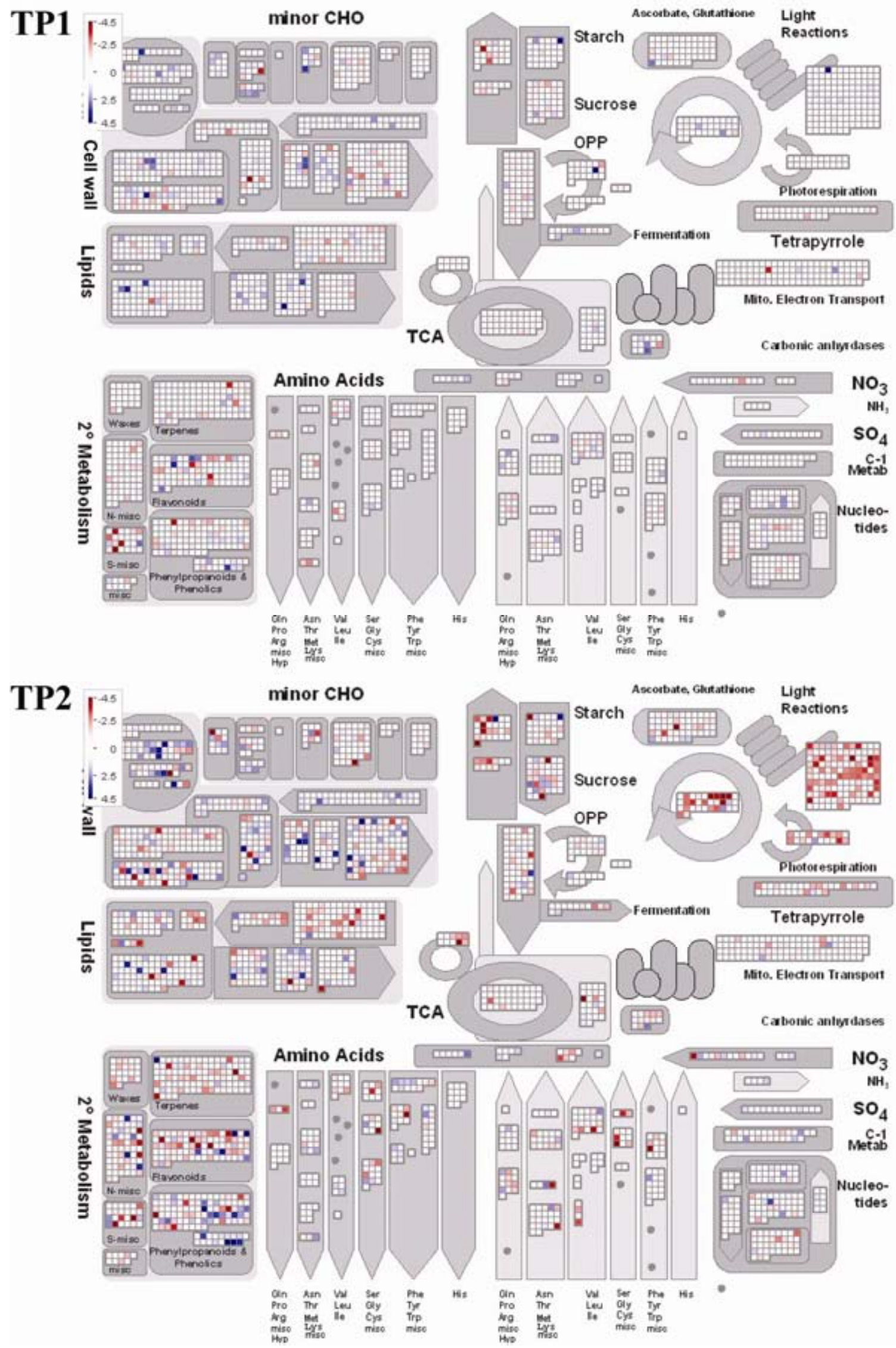

Fig. 2. MAPMAN sketch of metabolic pathways comparing up- and downregulated genes from control and infected roots at timepoints 1 (10 days after inoculation [dai]) (upper panel) and 2 (23 dai) (lower panel). 
Genes involved in the synthesis or signaling of plant hormones were also differentially regulated (Fig. 4). Gibberellinrelated genes were mostly upregulated at the second timepoint during infection, which was also found for genes annotated with functions in brassinosteroid synthesis and signaling. As already shown in Table 1, the number of ABA-related genes was also upregulated at the second infection timepoint. For ethylenerelated genes, it was found that a greater number were either upor downregulated at the second timepoint as compared with the first timepoint. Those downregulated included several genes encoding for proteins involved in ethylene synthesis (ArrayExpress E-MEXP-254). This is in agreement with the finding that a constitutively ethylene-overaccumulating mutant (eto2) showed slightly reduced disease index and root fresh weight (data not shown). Salicylic acid-related genes were found to be more downregulated at TP2, whereas genes associated with jasmonate synthesis and signaling were equally up- or downregulated at the two timepoints. However, there was a large overlap between the most highly upregulated genes in clubroots at the early timepoint as compared with jasmonic acid (JA)-inducible genes analyzed by using Genevestigator (Zimmermann et al. 2004), indicating a role for JA during root-gall development (Siemens et al. in press).

The concentrations of auxins and cytokinins have been shown previously to be increased in a root gall after infection with $P$. brassicae (Grsic-Rausch et al. 2000; Müller and Hilgenberg 1986). Transcript levels of genes related to auxin and cytokinin homeostasis were changed at the first timepoint, indicating a possible role of these hormones in disease development. The auxin-related genes nitrilase 1 and nitrilase 2 (NIT1 and NIT2), auxin-induced $G H 3$ homologs, and putative auxin transport proteins were predominantly upregulated ( $>2$ fold; Table 3 ). The enhanced expression of one or more nitrilases in A. thaliana during clubroot development confirmed a previous investigation (Grsic-Rausch et al. 2000). NIT1 and NIT2 were predominantly expressed in clubroot tissue, with an earlier peak during colonization of NIT1 and a second peak of NIT2 during maturation of pathogen spores (Grsic-Rausch et al. 2000). In Table 3, the two nitrilases are grouped together because the respective oligonucleotides on the ATH1 chip are not able to distinguish between the two isoforms. In addition, we found several $A u x / I A A$ genes and auxin response factors to be differentially expressed and, although most of the $A u x / I A A$ genes were downregulated (Table $3)$, there was no consistent pattern.

Strikingly, two of seven known putative cytokinin biosynthesis genes as well as cytokinin oxidases/dehydrogenases 1 and 6 (AtCKX1, AtCKX6) were downregulated (Table 4). In contrast, the expression of gene AtCKX4 appeared to be upregulated by about twofold, but it was not possible to detect $C K X 4$ expression by $\beta$-glucuronidase (GUS) staining in promoter GUS lines (Fig. 5). The other AtCKX genes showed low expression in roots, without any indication for preferable expression in specific cell types or tissues and, also, no response to clubroot infection. The response regulator genes ARRIO and

\section{Transporter}

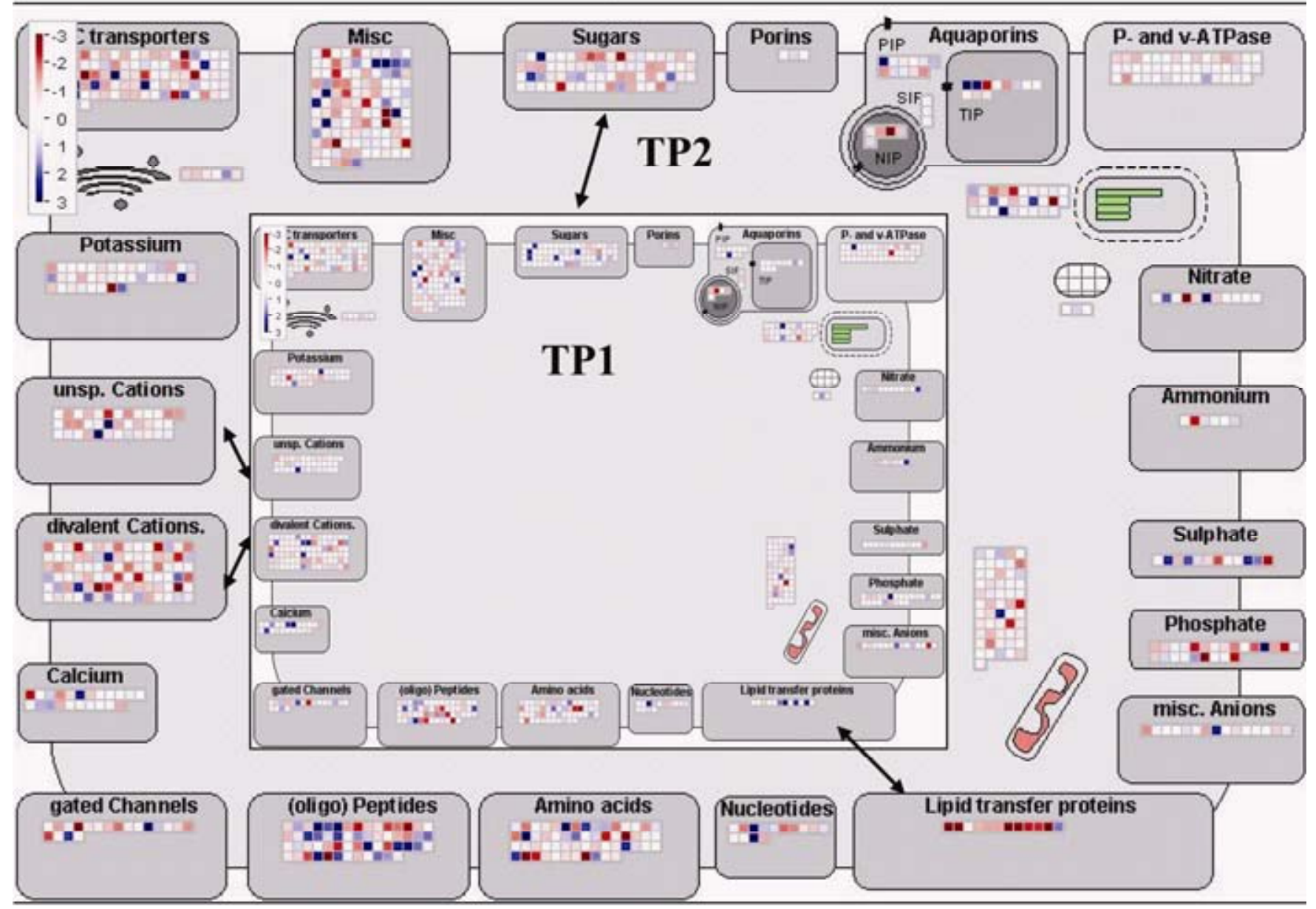

Fig. 3. MAPMAN sketch of transport-related genes up- and down-regulated from control and infected roots at timepoints 1 (10 days after inoculation [dai]) (inset) and 2 (23 dai). The arrows denote specifically highly upregulated gene families. 
$A R R 5$, which are involved in cytokinin signaling, and the cytokinin receptor gene $C R E 1 / A H K 4$ were upregulated by a factor of 4.7, 2.3, and 2.8, respectively, at the first timepoint. A reducetion of the degradation capacity for cytokinins by inhibition of specific $C K X$ genes could, in turn, result in an increased content of cytokinins. To further test the putative role of cytokinin oxidase/dehydrogenase genes, their expression during disease development was further analyzed.

\section{Expression of cytokinin oxidase/dehydrogenase genes is inhibited during club development.}

The expression patterns of AtCKX1 and AtCKX6 during pathogenesis were confirmed by qualitative reverse transcription (RT)-PCR and promoter-reporter gene analysis to validate the reduced expression levels estimated in the microarray experiment. For both $A t C K X$ genes, a reduction in expression was found by RT-PCR in infected roots compared with controls (Fig. 5), especially at the second timepoint. In particular, AtCKX1 expression was no longer detectable in infected roots. It has been shown in different publications that there is not a strict linear relationship between signal strength and the amount of transcripts for different genes with hybridizationbased technologies, such as Affymetrix chips (Czechowski et al. 2004, 2005; Holland 2002).
Therefore, a second approach was used to verify the downregulation of $A t C K X$ genes during clubroot. Using promoterreporter gene fusions, $A t C K X 1$ expression was found in control roots 24 and 37 days after germination (dag) only at rootbranching points at the bases of lateral roots. In infected roots, the AtCKX1 expression appeared to be reduced at early timepoints during disease development due to the reduced amounts of fine roots, and no expression was observed at late disease stages, since lateral roots were basically not present in infected roots (Fig. 6). For AtCKX4, the overall expression level was low and could therefore not been detected in roots using GUS reporter lines (Fig. 6), although according to the microarray data, gene expression was slightly upregulated at the second timepoint (Table 4). In contrast, AtCKXI is more prominently expressed in specific root tissues, such as root branching points (Fig. 6; magnification), and therefore, it was possible to observe GUS staining.

The GUS gene under the control of the AtCKX6 promoter is strongly expressed throughout the whole root-vascular cylinder in control roots (Werner et al. 2003). In infected roots, an apparent slight reduction of GUS staining was already observed 7 dai, which was further reduced at 14 dai (Fig. 6). When the clubroot symptoms were fully developed ( 21 and 28 dai), GUS staining was only rarely observed in line $C K X 6:: G U S$, indicat-

Table 1. Strong upregulation of transcripts from infected roots of plants ${ }^{\mathrm{a}}$

\begin{tabular}{|c|c|c|}
\hline AGI No. & Upregulation & Description \\
\hline AT5G59310 & 663.576923 & Lipid transfer protein 4 (LTP4) \\
\hline AT2G38540 & 324.467391 & Nonspecific lipid transfer protein 1 (LTP1) \\
\hline AT3G17520 & 173.923077 & Late embryogenesis abundant domain-containing protein \\
\hline AT5G22460 & 141.323944 & Esterase/lipase/thioesterase family protein \\
\hline AT1G61800 & 124.41555 & Glucose-6-phosphate/phosphate translocator \\
\hline AT1G56600 & 108.659574 & Galactinol synthase \\
\hline AT2G16890 & 94.9148936 & UDP-glucoronosyl/UDP-glucosyl transferase family protein \\
\hline AT3G59060 & 89.5128205 & Basic helix-loop-helix (bHLH) family protein \\
\hline AT5G66400 & 81.0649137 & Dehydrin (RAB18) \\
\hline AT4G36700 & 71.1186441 & Cupin family protein low similarity to preproMP27-MP32 from Cucurbita \\
\hline AT3G29970 & 67.787234 & Germination protein-related similar to HvB12D \\
\hline AT2G35300 & 55.1891892 & Late embryogenesis abundant group 1 domain-containing protein \\
\hline AT1G80130 & 54.7892977 & Expressed protein \\
\hline AT2G45190 & 54.2093023 & Axial regulator YABBY1 \\
\hline AT1G62510 & 54.0241935 & Protease inhibitor/seed storage/lipid transfer protein (LTP) family protein \\
\hline AT1G64110 & 53.772 & AAA-type ATPase family protein \\
\hline AT5G59320 & 53.2721823 & Lipid transfer protein 3 (LTP3) \\
\hline AT5G20790 & 52.5616438 & Expressed protein predicted protein \\
\hline AT1G52690 & 46.0797774 & Late embryogenesis abundant protein, putative \\
\hline AT4G15210 & 41.3146998 & Beta-amylase (BMY1) \\
\hline AT4G02280 & 40.8377358 & Sucrose synthase, putative \\
\hline AT5G06760 & 38.9385965 & Late embryogenesis abundant group 1 domain-containing protein \\
\hline AT1G62290 & 38.518018 & Aspartyl protease family protein \\
\hline AT3G28220 & 35.4317618 & $\begin{array}{l}\text { Meprin and TRAF homology domain-containing protein/MATH domain-containing protein similar to } \\
\text { ubiquitin-specific protease } 12\end{array}$ \\
\hline AT5G25110 & 33.3690476 & CBL-interacting protein kinase 25 (CIPK25) \\
\hline AT5G25610 & 32.8583815 & Dehydration-responsive protein (RD22) \\
\hline AT3G50440 & 31.1242485 & Hydrolase, alpha/beta fold family protein similar to ethylene-induced esterase \\
\hline AT1G72260 & 30.5280595 & Thionin (THI2.1) \\
\hline AT1G01140 & 30.2142857 & CBL-interacting protein kinase 9 (CIPK9) \\
\hline AT2G33380 & 29.6440367 & Calcium-binding RD20 protein (RD20) induced by abscisic acid during dehydration \\
\hline AT5G13170 & 28.2521994 & Nodulin MtN3 family protein similar to MtN3; identical to senescence-associated protein (SAG29) mRNA \\
\hline AT2G21820 & 26.9281915 & Expressed protein \\
\hline AT5G50360 & 26.5337423 & Expressed protein \\
\hline AT1G32900 & 26.080292 & Starch synthase \\
\hline AT1G73010 & 24.3142984 & Expressed protein similar to phosphatase, orphan 1 \\
\hline AT3G21670 & 23.3426573 & Nitrate transporter (NTP3) \\
\hline AT2G47770 & 23.3059273 & Benzodiazepine receptor-related \\
\hline AT2G45130 & 22.6820276 & SPX (SYG1/Pho81/XPR1) domain-containing protein weak similarity to NUC-2 \\
\hline AT1G16850 & 21.8180495 & Expressed protein \\
\hline AT3G17790; & 21.63 & [AT3G17790, acid phosphatase type 5 (ACP5) \\
\hline AT3G17800 & & [AT3G17800, expressed protein] \\
\hline AT1G22160 & 20.983209 & Senescence-associated protein-related; similar to senescence-associated protein SAG102 \\
\hline AT2G18050 & 20.4244373 & Histone H1-3 (HIS1-3) \\
\hline
\end{tabular}

${ }^{\text {a }}$ Upregulation $>20$ fold from infected roots of plants at 23 vs. 10 days postinfection. 
ing a strong downregulation of the gene. In cross-sections of root galls, only occasionally stained cells were observed in CKX6::GUS plants, whereas in control plants the central cylinder showed staining (Fig. 7). To exclude the possibility that we have missed subtle changes in other $C K X$ genes, we have investigated all available $C K X:: G U S$ lines (Werner et al. 2003). Only the lines $C K X 1:: G U S$ and $C K X 6:: G U S$ gave staining patterns in control and infected roots, whereas all other lines did not show any GUS staining (data not shown). This is in agreement with the observations that $A t C K X 2, A t C K X 3$, and AtCKX5 were not differentially expressed in the microarray experiment (data not shown).

Since, at this timepoint, a large proportion of cells might be affected by the pathogen so that gene function is already generally disturbed, we compared GUS activity in lines harboring a cytokinin-responsive promoter (ARR5::GUS) and an auxinresponsive promotor $(D R 5:: G U S)$. After infection, these lines showed clearly an increase in GUS activity in infected versus control roots, indicating an increased responsiveness to cytokinin and auxin as well as an increased content of the two hormones in infected roots as compared with controls during early and late infection, respectively (Fig. 6). Cross-sections showed an increase in the number of GUS-stained cells in line ARR 5::GUS (Fig 7). This also demonstrated that the transcription and translation machinery of infected cells at this timepoint was still intact.

\section{Enhanced degradation of cytokinin causes pathogen resistance.}

The clubroot disease symptoms of different transgenic lines overproducing AtCKX genes (35S::AtCKX1, 35S::AtCKX2, 35S:AtCKX3) were compared with the susceptible ecotype Col-0 (Table 5). The lines used in this study were described in detail by Werner and associates (2003), and lines with high ex-

Table 2. Strong downregulation of transcripts from infected roots ${ }^{\mathrm{a}}$

\begin{tabular}{|c|c|c|}
\hline AGI No. & Downregulation & Description \\
\hline AT2G01520 & 0.00494234 & Major latex protein-related; Pathogenesis-related protein Bet v I family \\
\hline AT4G11190 & 0.00535777 & Disease resistance-responsive family protein \\
\hline AT4G33720 & 0.00715789 & Pathogenesis-related protein (PR-1) \\
\hline AT4G13290 & 0.00742804 & Cytochrome P450 71A19 \\
\hline AT3G01190 & 0.00819912 & Peroxidase 27 (PER27) (PRXR7) \\
\hline AT4G11310 & 0.00830424 & Cysteine proteinase, similar RD21A (thiol protease) \\
\hline AT1G14120 & 0.01290265 & $\begin{array}{l}\text { 2-Oxoglutarate-dependent dioxygenase, putative similar to adventitious rooting related oxygenase ARRO-1, } \\
\text { 2OG-Fe(II) oxygenase superfamily }\end{array}$ \\
\hline AT2G05510 & 0.01421622 & Glycine-rich protein \\
\hline AT1G12010 & 0.01580135 & 1-Aminocyclopropane-1-carboxylate oxidase \\
\hline AT4G15390 & 0.01602223 & Transferase family protein similar to alcohol acyltransferase \\
\hline AT4G11290 & 0.01701149 & Peroxidase, putative identical to peroxidase ATP19a \\
\hline AT3G26460 & 0.02437474 & Major latex protein-related/MLP-related low similarity to major latex protein \\
\hline AT1G35910 & 0.02508711 & Trehalose-6-phosphate phosphatase \\
\hline AT1G13420 & 0.02543413 & Sulfotransferase family protein similar to steroid sulfotransferase 1 \\
\hline AT3G17690 & 0.02552553 & Cyclic nucleotide-binding transporter 2/CNBT2 \\
\hline AT4G22212 & 0.02697634 & Expressed protein \\
\hline AT1G49860 & 0.02754846 & Glutathione S-transferase \\
\hline AT5G53250 & 0.02897083 & Arabinogalactan-protein, putative (AGP22) \\
\hline AT1G77380 & 0.02913843 & Amino acid carrier, putative \\
\hline AT3G49620 & 0.02923602 & 2-Oxoacid-dependent oxidase, putative (DIN11) \\
\hline AT4G30140 & 0.03103892 & GDSL-motif lipase/hydrolase family protein \\
\hline AT1G66280; & 0.03331564 & [AT1G66280, glycosyl hydrolase family 1 protein ; \\
\hline AT1G66270 & & [AT1G66270, beta-glucosidase (PSR3.2), similar to thioglucoside glucohydrolase \\
\hline AT5G62550 & 0.03354065 & Expressed protein \\
\hline AT1G70830; & 0.0336562 & [AT1G70830, Bet v I allergen family protein similar to Csf-2; \\
\hline AT1G70850 & & [AT1G70850, Bet v I allergen family protein similar to Csf-2 \\
\hline AT1G32970 & 0.03367232 & Subtilase family protein \\
\hline AT1G02900 & 0.03454384 & Rapid alkalinization factor (RALF) family protein \\
\hline AT4G29690 & 0.03469415 & Type I phosphodiesterase/nucleotide pyrophosphatase family protein \\
\hline AT1G30760 & 0.03512088 & $\begin{array}{l}\text { FAD-binding domain-containing protein similar to SP|P30986 reticuline oxidase precursor (Berberine-bridge- } \\
\text { forming enzyme) (BBE) }\end{array}$ \\
\hline AT5G63590 & 0.03700167 & Flavonol synthase 1 (EC 1.14.11.-) (FLS 1) ) \\
\hline AT5G59090 & 0.03835467 & Subtilase family protein contains similarity to prepro-cucumisin \\
\hline AT5G26280 & 0.03989849 & [AT5G26280, meprin and TRAF homology domain-containing protein/MATH domain-containing protein low \\
\hline AT5G26260 & & similarity to ubiquitin-specific protease 12 \\
\hline & & [AT5G26260, meprin and TRAF homology domain-containing protein \\
\hline AT1G16530 & 0.0400165 & $\begin{array}{l}\text { LOB domain protein 3/lateral organ boundaries domain protein } 3 \text { (LBD3); identical to ASYMMETRIC } \\
\text { LEAVES2-like protein } 9\end{array}$ \\
\hline AT3G48360 & 0.04030483 & Speckle-type POZ protein-related \\
\hline AT4G29270 & 0.0418041 & Acid phosphatase class B family protein \\
\hline AT1G31710 & 0.04204532 & Copper amine oxidase \\
\hline AT5G45700 & 0.04235808 & NLI interacting factor (NIF) family protein \\
\hline AT5G35940 & 0.04326599 & Jacalin lectin family protein similar to myrosinase-binding protein homolog \\
\hline AT4G24340 & 0.04386844 & Phosphorylase family protein \\
\hline AT4G15100 & 0.04434949 & Serine carboxypeptidase S10 family protein \\
\hline AT1G45130 & 0.04495557 & Beta-galactosidase, putative/lactase \\
\hline AT4G04830 & 0.04546711 & $\begin{array}{l}\text { Methionine sulfoxide reductase domain-containing protein/SeIR domain-containing protein low similarity to } \\
\text { pilin-like transcription factor }\end{array}$ \\
\hline AT5G63600 & 0.04591183 & Flavonol synthase \\
\hline AT4G15700 & 0.04725139 & Glutaredoxin family protein (thioltransferase) \\
\hline AT3G23890 & 0.04916653 & DNA topoisomerase, ATP-hydrolyzing/DNA topoisomerase II/DNA gyrase (TOP2) \\
\hline
\end{tabular}

${ }^{a}$ Downregulation $<0.05$ fold from infected roots of plants 23 vs. 10 days postinfection. 
pression levels of the transgene were used (data not shown). Although the microarray data suggested a specific role for AtCXK1 and AtCKX6 only, we reasoned that overexpression of any $C K X$ gene or protein would result in the degradation of cytokinins and thus in a lower cytokinin content. The $C K X$ genes used in this experiment showed different cellular localization (Werner et al. 2003), making those interesting tools to investigate the effect of the cellular localization of cytokinins for clubroot development.

Resistance to clubroot is defined by the reduction of root weight that is correlated to gall size and reduction of resting spores and a lower disease index (DI) (Siemens et al. 2002). Ecotype Col-0 showed the typical disease indices (DI > 90) and root indices (roots of infected plants/roots of not infected plants $\left(\mathrm{R}_{\mathrm{i}} / \mathrm{R}_{\mathrm{ni}}\right)>2$ ) of susceptible lines (Siemens et al. 2002). The plants showed clubs that were extended over the whole hypocotyl and also, in part, into the rosette ground (Fig. 8). In contrast, the overproduction of AtCKX1 (35S::AtCKX1) and $A t C K X 3$ (35S::AtCKX3) caused an apparent resistance to $P$. brassicae isolate ' $\mathrm{e}_{\mathrm{H}}$ ', but the overexpression of $A t C K X 2$ (35S::AtCKX2) had only very limited influence on clubroot disease. Severe swellings were rarely observed after inoculation in the roots of line $35 S:: A t C K X 1$, resulting in low disease indices. The plants appeared similar to noninoculated control plants (Fig. 8). After infection the main root of $35 S:: A t C K X 1$ often showed reduced growth and undulation. The pathogen was sometimes able to induce a small hypocotyl gall (Fig. 8). In line 35S::AtCKX3, scoring of clubroot symptoms always revealed a significant difference from those of Columbia; clubs were induced less frequently and infected roots showed greater variation of disease symptoms (Table 5). In contrast, line 35S::AtCKX2 showed only slight differences as compared with Columbia, which were, in most experimental series, not significant even with reduced inoculation pressure (data not shown). However, although the root indices indicate susceptibility of this line, the mean root index was significantly lower than the index of Col-0. In summary, the root indices of the investigated transgenic lines gave indications of induced tolerance by overexpression of $C K X$ genes.

Three additional isolates were used to test clubroot tolerance of $C K X$ overexpressors. Lines $35 S:: A t C K X 1$ and $35 S:: A t C K X 3$

Table 3. Down- $(<0.5 \times)$ and upregulated genes $(>2 \times)$ related to auxin synthesis, metabolism, transport, and gene regulation ${ }^{\mathrm{a}}$

\begin{tabular}{|c|c|c|c|c|c|c|c|}
\hline \multirow[b]{4}{*}{ AGI No. } & \multirow[b]{4}{*}{ Gene annotation } & \multicolumn{4}{|c|}{ Expression level $^{\text {b }}$} & & \\
\hline & & \multicolumn{2}{|c|}{ Timepoint 1} & \multicolumn{2}{|c|}{ Timepoint 2} & \multirow{2}{*}{\multicolumn{2}{|c|}{ Mean ratio of induction }} \\
\hline & & Control & Inoc. & Control & Inoc. & & \\
\hline & & (24 dag) & (10 dpi) & (37 dag) & (23 dpi) & Timepoint $1^{\mathrm{c}}$ & Timepoint $2^{d}$ \\
\hline At2g23170 & Auxin-responsive $G H 3$ family protein & 1.8 & 162.5 & 1.7 & 229.2 & $92.0 \pm 61.5$ & $137.5 \pm 40.5$ \\
\hline Atlg72540 & Dual specificity cytosolic kinase & 0.8 & 38.1 & 6.1 & 124.9 & $47.6 \pm 8.2$ & $20.5 \pm 13.1$ \\
\hline At5g13360 & Auxin-responsive $G H 3$ family protein & 19.8 & 67.1 & 16.4 & 164.2 & $3.4 \pm 0.9$ & $10.0 \pm 3.8$ \\
\hline At4g34760 & Auxin-induced protein X15 & 19.6 & 65.6 & 43.1 & 64.1 & $3.4 \pm 1.2$ & $1.5 \pm 19.8$ \\
\hline At1g77690 & Amino acid permease. similar to $A U X 1$ & 92.7 & 290.9 & 225.7 & 27.6 & $3.1 \pm 0.5$ & $0.1 \pm 0.3$ \\
\hline At1g73590 & Auxin efflux carrier protein. putative (PIN1) & 56.2 & 176.5 & 123.8 & 76.0 & $3.1 \pm 0.5$ & $0.6 \pm 0.3$ \\
\hline At2g32410 & Auxin-resistance protein $(A X R 1)$ & 23.7 & 61.2 & 35.5 & 28.1 & $2.6 \pm 0.4$ & $0.8 \pm 0.1$ \\
\hline At4g34750 & Auxin-responsive protein & 23.4 & 58.2 & 38.2 & 21.3 & $2.5 \pm 0.6$ & $0.6 \pm 20.2$ \\
\hline At1g28130 & Auxin-responsive $G H 3$ family & 37.2 & 91.9 & 43.7 & 70.9 & $2.5 \pm 0.4$ & $1.6 \pm 19.7$ \\
\hline At2g33860 & Auxin-responsive factor $(A R F 3)$ & 70.7 & 161.7 & 99.7 & 245.8 & $2.3 \pm 0.3$ & $2.5 \pm 1.0$ \\
\hline At5g37020 & Auxin-responsive factor $(A R F 8)$ & 84.7 & 178.4 & 134.8 & 206.3 & $2.1 \pm 0.3$ & $1.5 \pm 0.4$ \\
\hline At1g70940 & Auxin transport protein. putative (PIN3) & 83.2 & 173.5 & 138.7 & 200.9 & $2.1 \pm 0.4$ & $1.4 \pm 0.5$ \\
\hline At4g02980 & Auxin-binding protein $1(A B P 1)$ & 73.3 & 150.8 & 90.2 & 166.7 & $2.1 \pm 0.2$ & $1.8 \pm 0.4$ \\
\hline At2g14960 & Auxin-responsive $G H 3$ family & 21.4 & 43.4 & 14.2 & 17.1 & $2.0 \pm 1.5$ & $1.2 \pm 0.6$ \\
\hline At1g48630 & Activated protein kinase $\mathrm{C}$ receptor & 514.7 & 1021.0 & 583.5 & 262.7 & $2.0 \pm 0.2$ & $0.5 \pm 0.2$ \\
\hline At3g12830 & Auxin-responsive family protein & 84.6 & 154.4 & 35.9 & 137.5 & $1.8 \pm 0.4$ & $3.8 \pm 2.9$ \\
\hline At3g44310; & AT3g44310. nitrilase 1 (NIT1) & & & & & & \\
\hline At3g44300 & AT3g44300. nitrilase 2 (NIT2) * & 410.7 & 632.1 & 348.4 & 2565.7 & $1.5 \pm 0.3$ & $7.4 \pm 2.8$ \\
\hline At5g01990 & Auxin efflux carrier family protein & 46.3 & 65.1 & 37.1 & 178.5 & $1.4 \pm 0.1$ & $4.8 \pm 1.6$ \\
\hline At4g37390; & AT4g37390. auxin-responsive $G H 3$ family & & & & & & \\
\hline At1g59500 & AT1g59500. auxin-responsive $G H 3$ family protein & 27.8 & 36.1 & 2.3 & 70.9 & $1.3 \pm 0.5$ & $31.3 \pm 9.1$ \\
\hline Atlg77850 & Transcriptional factor B3 family protein & 34.9 & 43.0 & 51.7 & 22.6 & $1.2 \pm 0.5$ & $0.4 \pm 0.3$ \\
\hline At4g38840 & Auxin-responsive protein & 16.6 & 19.5 & 18.1 & 38.4 & $1.2 \pm 0.3$ & $2.1 \pm 19.5$ \\
\hline At4g14550 & Auxin-responsive protein (IAA14) & 21.4 & 24.3 & 15.3 & 76.1 & $1.1 \pm 0.2$ & $5.0 \pm 1.9$ \\
\hline At4g03400 & Auxin-responsive $G H 3$ family & 17.1 & 18.9 & 13.3 & 97.4 & $1.1 \pm 0.3$ & $7.3 \pm 2.9$ \\
\hline At5g35580 & Protein kinase & 243.9 & 250.2 & 399.6 & 41.5 & $1.0 \pm 0.3$ & $0.1 \pm 0.4$ \\
\hline At1g19850 & Transcription factor MONOPTEROS (IAA24) & 183.8 & 181.6 & 225.0 & 83.9 & $1.0 \pm 0.0$ & $0.4 \pm 0.3$ \\
\hline At4g00880 & Auxin-responsive family protein & 154.1 & 141.7 & 355.0 & 52.3 & $0.9 \pm 0.2$ & $0.1 \pm 0.3$ \\
\hline At2g21050 & Amino acid permease, similar to $A U X 1$ & 93.1 & 87.6 & 246.8 & 54.7 & $0.9 \pm 0.1$ & $0.2 \pm 0.3$ \\
\hline At3g23050 & $\begin{array}{l}\text { Auxin-responsive protein/indoleacetic acid-induced protein } 7 \\
\text { (IAA7) }\end{array}$ & 45.9 & 37.7 & 26.7 & 135.6 & $0.8 \pm 0.2$ & $5.1 \pm 1.7$ \\
\hline At2g22670 & $\begin{array}{l}\text { Auxin-responsive protein/indoleacetic acid-induced protein } 8 \\
\text { (IAA8) }\end{array}$ & 1319.9 & 1038.7 & 1503.3 & 641.4 & $0.8 \pm 0.1$ & $0.4 \pm 0.2$ \\
\hline At4g17280 & Auxin-responsive family protein & 46.1 & 36.1 & 51.8 & 16.6 & $0.8 \pm 0.1$ & $0.3 \pm 0.3$ \\
\hline At4g27260 & Auxin-responsive $G H 3$ family protein & 66.1 & 48.8 & 34.2 & 190.0 & $\begin{array}{l}0.7 \pm 0.2 \\
\text { (Continued onf }\end{array}$ & $\begin{array}{l}5.6 \pm 2.0 \\
\text { ollowing page })\end{array}$ \\
\hline
\end{tabular}

\footnotetext{
${ }^{a}$ Differentially influenced by Plasmodiophora brassicae in infected and not inoculated plants of ecotype Col-0 at two timepoints after inoculation. All values are normalized to the expression level of not inoculated Col-0 plants at the corresponding timepoint. Mean values of expression levels of three independent experiments and the mean values of induction and standard deviations are given. *NIT1 and NIT2 can not be distinguished on the microarray by the oligonucleotides used.

${ }^{\mathrm{b}}$ dag = days after germination; dpi = days postinfection.

c $10 \mathrm{dpi} / 24 \mathrm{dag} \pm \mathrm{SD}$ (standard deviation).

d $23 \mathrm{dpi} / 37 \mathrm{dag} \pm \mathrm{SD}$.
} 
exhibited significant tolerance to all tested isolates (Table 5). On the contrary, the scoring and the root index of the line $35 S:: C K X 2$ showed an induced tolerance, significantly only to isolate ' $\mathrm{k}_{1}$ ' but not to isolates ' $1 \mathrm{CK}$ ' and ' $\mathrm{e}_{2}$ ' (Table 5).

To further analyze the effect of $A t C K X$ overexpression in root galls with respect to endogenous cytokinins, we have conducted an experiment using a homozygous line of the gene constructs $35 S:: A t C K X 1$ and ARR5::GUS to demonstrate the downregulation of endogenous cytokinins in infected roots. In comparison with the ARR5::GUS line, this line showed a strongly reduced expression pattern of GUS in control roots as well as in infected roots, indicating a reduced cytokinin level in the roots (Fig. 9). As described for 9-day-old young seedlings (Werner et al. 2003), the detectable GUS expression in roots of this line was also restricted to root meristems and to the central cylinder in 24- and 35-day-old plants and the corresponding plants 14 and 21 dai (Fig. 9).

\section{DISCUSSION}

The clubroot disease of the family Brassicaceae is an important and damaging disease within this plant family. To obtain insight in the pathogenesis process, we have investigated the transcriptome of Arabidopsis thaliana after infection with Plasmodiophora brassicae at two developmentally distinct timepoints. Several observations were made that relate to the general biology of this interaction.

i) Genes involved in cell division and expansion, such as cell cycle genes and expansins, are upregulated, especially at the first analyzed timepoint of the disease. This is in accordance with the morphology of a club and the timing of cell division and cell enlargement during the development of a club (Kobelt et al. 2000).

ii) Although club cells are heavily infected with $P$. brassicae, there are surprisingly few resistance responses observed. The microarray data indicate that most known defense- or resistance-related genes are either not differentially expressed or downregulated. Ito and associates (1996) described proteins with homology to pathogenesis-related (PR) protein group 5 that were enhanced during a susceptible response. A study on PR-proteins during pathogenesis showed no clear correlation between the activity of peroxidase and chitinase isoenzymes in roots of a susceptible and a resistant cultivar of Chinese cabbage and resistance or tolerance to clubroot (Ludwig-Müller et

\begin{tabular}{|c|c|c|c|c|c|c|c|}
\hline \multirow[b]{4}{*}{ AGI No. } & \multirow[b]{4}{*}{ Gene annotation } & \multicolumn{4}{|c|}{ Expression level $^{b}$} & & \\
\hline & & \multicolumn{2}{|c|}{ Timepoint 1} & \multicolumn{2}{|c|}{ Timepoint 2} & & \\
\hline & & \multirow{2}{*}{$\begin{array}{l}\text { Control } \\
\text { (24 dag) }\end{array}$} & \multirow{2}{*}{$\begin{array}{c}\text { Inoc. } \\
\text { (10 dpi) }\end{array}$} & \multirow{2}{*}{$\begin{array}{l}\text { Control } \\
\text { (37 dag) }\end{array}$} & \multirow{2}{*}{$\begin{array}{c}\text { Inoc. } \\
\text { (23 dpi) }\end{array}$} & \multicolumn{2}{|c|}{ Mean ratio of induction } \\
\hline & & & & & & Timepoint $\mathbf{1}^{\mathrm{c}}$ & Timepoint $2^{\mathrm{d}}$ \\
\hline At1g51780 & $\begin{array}{l}\text { Indole 3-acetic acid (IAA)-amino acid hydrolase 5/auxin } \\
\text { conjugate hydrolase (ILL5) }\end{array}$ & 236.2 & 173.2 & 288.0 & 104.1 & $0.7 \pm 0.0$ & $0.4 \pm 0.3$ \\
\hline At4g36110 & Auxin-responsive protein & 29.1 & 21.2 & 15.4 & 38.3 & $0.7 \pm 0.2$ & $2.5 \pm 0.8$ \\
\hline At2g33310 & $\begin{array}{l}\text { Auxin-responsive protein/indoleacetic acid-induced protein } 13 \\
(\text { IAA13) }\end{array}$ & 409.8 & 277.3 & 669.0 & 323.6 & $0.7 \pm 0.1$ & $0.5 \pm 0.2$ \\
\hline At5g20730 & Auxin-responsive factor (ARF7) & 170.3 & 108.4 & 178.7 & 80.4 & $0.6 \pm 0.1$ & $0.4 \pm 0.2$ \\
\hline At4g27450 & $\begin{array}{l}\text { Expressed protein similar to auxin down-regulated protein } \\
\text { ARG10 }\end{array}$ & 690.5 & 426.3 & 385.0 & 1969.9 & $0.6 \pm 0.2$ & $5.1 \pm 2.5$ \\
\hline At1g04250 & $\begin{array}{l}\text { Auxin-responsive protein/indoleacetic acid-induced protein } 17 \\
\text { (IAA17) }\end{array}$ & 441.4 & 249.3 & 466.9 & 221.7 & $0.6 \pm 0.1$ & $0.5 \pm 0.2$ \\
\hline At3g16500 & Auxin-responsive Aux/IAA family protein & 254.9 & 139.5 & 284.4 & 123.6 & $0.5 \pm 0.1$ & $0.4 \pm 0.2$ \\
\hline At2g04850 & Auxin-responsive protein-related & 57.5 & 29.2 & 133.1 & 6.9 & $0.5 \pm 0.2$ & $0.1 \pm 0.0$ \\
\hline At2g46370 & Auxin-responsive $G H 3$ family protein & 357.1 & 179.7 & 313.7 & 142.0 & $0.5 \pm 0.2$ & $0.5 \pm 0.2$ \\
\hline At1g56220 & Dormancy/auxin associated family protein & 551.7 & 264.1 & 205.9 & 705.6 & $0.5 \pm 0.1$ & $3.4 \pm 1.7$ \\
\hline At2g46690 & Auxin-responsive family protein & 533.7 & 251.1 & 941.6 & 76.4 & $0.5 \pm 0.1$ & $0.1 \pm 0.4$ \\
\hline At5g53590 & Auxin-responsive family protein & 1787.8 & 813.1 & 1497.7 & 405.9 & $0.5 \pm 0.0$ & $0.3 \pm 0.3$ \\
\hline At4g12980 & Auxin-responsive protein & 133.1 & 60.0 & 179.9 & 36.2 & $0.5 \pm 0.1$ & $0.2 \pm 0.3$ \\
\hline At3g15460; & AT3G15460. brix domain-containing protein & & & & & & \\
\hline At3g15450 & AT3g15450. expressed protein & 2935.7 & 1246.0 & 1650.0 & 472.0 & $0.4 \pm 0.1$ & $0.3 \pm 0.3$ \\
\hline Atlg75590 & Auxin-responsive family protein & 29.9 & 11.8 & 23.6 & 19.1 & $0.4 \pm 0.1$ & $0.8 \pm 0.5$ \\
\hline At1g04100 & $\begin{array}{l}\text { Auxin-responsive protein/indoleacetic acid-induced protein } 10 \\
(I A A 10)\end{array}$ & 160.7 & 56.0 & 115.2 & 69.3 & $0.3 \pm 0.0$ & $0.6 \pm 0.5$ \\
\hline At5g25890 & $\begin{array}{l}\text { Auxin-responsive protein/indoleacetic acid-induced protein } 28 \\
\text { (IAA28) }\end{array}$ & 319.6 & 101.7 & 288.6 & 80.7 & $0.3 \pm 0.1$ & $0.3 \pm 0.3$ \\
\hline At5g20820 & Auxin-responsive protein-related & 70.4 & 21.7 & 82.1 & 48.5 & $0.3 \pm 0.1$ & $0.6 \pm 0.6$ \\
\hline At1g04240 & $\begin{array}{l}\text { Auxin-responsive protein/indoleacetic acid-induced protein } 3 \\
(I A A 3)\end{array}$ & 131.2 & 37.8 & 130.1 & 39.6 & $0.3 \pm 0.1$ & $0.3 \pm 0.3$ \\
\hline At3g23030 & $\begin{array}{l}\text { Auxin-responsive protein/indoleacetic acid-induced protein } 2 \\
(I A A 2)\end{array}$ & 529.6 & 150.5 & 587.9 & 218.7 & $0.3 \pm 0.0$ & $0.4 \pm 0.3$ \\
\hline At4g29080 & Auxin-responsive Aux/IAA family protein & 959.6 & 262.1 & 1469.5 & 99.1 & $0.3 \pm 0.0$ & $0.1 \pm 0.4$ \\
\hline At1g51950 & $\begin{array}{l}\text { Auxin-responsive protein/indoleacetic acid-induced protein } 18 \\
(I A A 18)\end{array}$ & 441.3 & 117.9 & 675.5 & 137.8 & $0.3 \pm 0.1$ & $0.2 \pm 0.3$ \\
\hline At1g15580 & $\begin{array}{l}\text { Auxin-responsive protein/indoleacetic acid-induced protein } 5 \\
\text { (IAA5) }\end{array}$ & 32.2 & 8.1 & 69.8 & 4.1 & $0.3 \pm 0.2$ & $0.1 \pm 0.1$ \\
\hline At3g47620 & TCP family transcription factor & 475.2 & 110.5 & 364.4 & 374.1 & $0.2 \pm 0.0$ & $1.0 \pm 0.2$ \\
\hline At5g19140 & Auxin/aluminum-responsive protein & 898.3 & 196.7 & 875.7 & 925.6 & $0.2 \pm 0.1$ & $1.1 \pm 0.1$ \\
\hline At4g22620 & Auxin-responsive family protein & 172.3 & 35.7 & 180.7 & 41.0 & $0.2 \pm 0.1$ & $0.2 \pm 0.3$ \\
\hline At3g15540 & $\begin{array}{l}\text { Auxin-responsive protein/indoleacetic acid-induced protein } 19 \\
\text { (IAA19) }\end{array}$ & 276.2 & 56.2 & 330.8 & 56.3 & $0.2 \pm 0.1$ & $0.2 \pm 0.3$ \\
\hline At3g04730 & $\begin{array}{l}\text { Auxin-responsive protein/indoleacetic acid-induced protein } 16 \\
\text { (IAA16) }\end{array}$ & 765.4 & 98.8 & 501.8 & 188.8 & $0.1 \pm 0.0$ & $0.4 \pm 0.3$ \\
\hline At3g60690 & Auxin-responsive family protein & 673.5 & 86.7 & 190.5 & 49.5 & $0.1 \pm 0.0$ & $0.3 \pm 0.5$ \\
\hline At2g45210 & Auxin-responsive protein & 314.1 & 36.0 & 58.7 & 62.4 & $0.1 \pm 0.0$ & $1.1 \pm 0.6$ \\
\hline
\end{tabular}


al. 1994). However, in the susceptible interaction, a novel chitinase and peroxidase isoenzyme was induced (Ludwig-Müller et al. 1994). Since a few genes are also upregulated, it can be speculated that there is an initial equilibrium between pathogen attack and host plant defense that is later shifted in favor to pathogen. It has been demonstrated in incompatible interactions in Arabidopsis that, during this stage of secondary colonization of the root gall, resistance mechanisms (such as hypersensitive response) to clubroot so far described are functional (Fuchs and Sacristán 1996; Kobelt et al. 2000).

iii) The balance between cytokinin and auxin may be of crucial importance. An involvement of plant hormones as pathogenicity factors is strongly indicated by the correlation of clubroot disease symptoms with an increase of auxin (Butcher et al. 1974; Ludwig-Müller et al. 1993, 1996) and cytokinin (Dekhuijzen and Overeem 1971), resulting in increased cell division and cell elongation. While it was previously shown that the host auxin metabolism is redirected towards the synthesis of more auxin via the nitrilase pathway in Arabidopsis (Grsic-Rausch et al. 2000), it was speculated that the increase in cytokinins is due to the formation of zeatin by the pathogen itself (Dekhuijzen 1981; Müller and Hilgenberg 1986). Concomitant measurement of auxin and cytokinin in young root galls of Chinese cabbage led to the hypothesis that a very early increase in IAA and IAA-conjugate synthesis during primary infection is followed by changes in the cytokinin pool by which P. brassicae creates its own sink (Devos et al. 2005). The induction of auxin correlates with an increase in seedling growth and xyloglucan endotransferase/hydrolase leading to cell elongation (Devos et al. 2005).

In the microarray experiment, it was found that nitrilases 1 and 2, which could not be separated by the oligonucleotides on the ATH1 array, were induced during club development, especially at the second timepoint in our investigation. This is in accordance with the increase in endogenous IAA content in infected Arabidopsis plants (Grsic-Rausch et al. 2000; LudwigMüller et al. 1999) as well as the increase in GUS-staining of the DR5::GUS line (Fig. 5). NIT1 and NIT2 are the nitrilase homologs predominantly expressed in clubroot tissue, and nitrilase was mainly localized in infected cells containing sporulating plasmodia (Grsic-Rausch et al. 2000). A nitrilase 1 mutant (nit1) was found to have reduced root-gall size and lower free IAA content in clubs (Grsic-Rausch et al. 2000; Neuhaus et al. 2000), underpinning the relevance of enhanced auxin synthesis for pathogenicity. In addition, the upregulation of several members of the GH3 gene family of Arabidopsis was observed. Several members of this family, including the GH3 genes upregulated during clubroot, are able to synthesize IAA amino-acid conjugates via adenylation (Staswick et al. 2002, 2005). Therefore, we hypothesize that not only the level of free IAA but also the total auxin pool is important for gall development.

On the contrary, most of the auxin-inducible $A u x / I A A$ genes, with the exception of two members, were either downregulated (Table 3) or not regulated at all. Mutants in auxin transport and auxin response did not show clear effects concerning a higher tolerance against clubroot (Siemens et al. 2002). Genes connected to signal transduction, such as the putative extracellular auxin receptor $A B P 1$ (Chen et al. 2001a and b; Steffens et al. 2001) and the intracellular auxin receptor TIRI (Dharmasiri et al. 2005; Kepinski and Leyser 2005), were not differentially regulated according to our criteria of twofold induction or decrease during club development. $A X R l$, which is part of the auxin-induced Aux/IAA degradation machinery via the $26 \mathrm{~S}$ proteasome (Leyser et al. 1993), was also not differentially expressed. These findings indicate that the integration of the auxin signal must be via other pathways. Maybe the downregulation of $A u x / I A A$ repressors of auxin-induced gene expression during pathogenesis is enough to increase the intracellular auxin response.

The microarray analysis has yielded additional indications that cytokinin plays an essential role during clubroot disease. Several genes coding for cytokinin signaling proteins and cytokinin metabolic enzymes showed altered expression levels.

Table 4. Down- $(<0.5 \times)$ and upregulated genes $(>2 \times)$ related to cytokinin metabolism and signaling ${ }^{a}$

\begin{tabular}{|c|c|c|c|c|c|c|c|}
\hline \multirow[b]{4}{*}{ AGI No. } & \multirow[b]{4}{*}{ Gene annotation } & \multicolumn{4}{|c|}{ Expression level $^{\mathrm{b}}$} & & \\
\hline & & \multicolumn{2}{|c|}{ Timepoint 1} & \multicolumn{2}{|c|}{ Timepoint 2} & \multirow{2}{*}{\multicolumn{2}{|c|}{ Mean ratio of induction }} \\
\hline & & \multirow{2}{*}{$\begin{array}{l}\text { Control } \\
\text { (24 dag) }\end{array}$} & \multirow{2}{*}{$\begin{array}{c}\text { Inoc. } \\
\text { (10 dpi) }\end{array}$} & \multirow{2}{*}{$\begin{array}{l}\text { Control } \\
\text { (37 dag) }\end{array}$} & \multirow{2}{*}{$\begin{array}{c}\text { Inoc. } \\
\text { (23 dpi) }\end{array}$} & & \\
\hline & & & & & & Timepoint $\mathbf{1}^{\mathrm{c}}$ & Timepoint $2^{\mathrm{d}}$ \\
\hline At4g31920 & Two-component response regulator protein $(A R R 10)$ & 28.9 & 136.5 & 54.3 & 87.4 & $4.7 \pm 0.5$ & $1.6 \pm 0.5$ \\
\hline At2g01830 & Histidine kinase (CRE1/AHK4) & 71.7 & 202.5 & 183.4 & 143.5 & $2.8 \pm 0.3$ & $0.8 \pm 0.3$ \\
\hline At3g48100 & Response regulator 5 (ARR5) & 75.3 & 175.3 & 295.4 & 94.2 & $2.3 \pm 0.6$ & $0.3 \pm 0.3$ \\
\hline Atlg10470 & Response regulator 4 (ARR4) & 283.0 & 340.1 & 382.5 & 120.5 & $1.2 \pm 0.1$ & $0.3 \pm 0.3$ \\
\hline Atlg74890 & Response regulator 15 (ARR15) & 23.6 & 25.5 & 34.3 & 15.1 & $1.1 \pm 0.2$ & $0.4 \pm 0.2$ \\
\hline At3g55950 & Protein kinase family & 234.5 & 251.6 & 292.0 & 95.8 & $1.1 \pm 0.2$ & $0.3 \pm 0.3$ \\
\hline At4g29740 & Cytokinin oxidase $(C K X 4)$ & 40.6 & 42.4 & 36.5 & 73.9 & $1.0 \pm 0.1$ & $2.0 \pm 0.5$ \\
\hline Atlg28230 & Purine permease $(P U P 1)$ & 39.6 & 32.7 & 29.9 & 103.4 & $0.8 \pm 0.2$ & $3.5 \pm 1.8$ \\
\hline At4g16420 & Transcriptional adaptor $(A D A 2 b)$ & 93.4 & 73.0 & 84.0 & 169.3 & $0.8 \pm 0.2$ & $2.0 \pm 0.4$ \\
\hline At3g19160 & Cytokinin synthase (IPT8) & 22.1 & 12.1 & 10.4 & 35.6 & $0.5 \pm 0.1$ & $3.4 \pm 2.6$ \\
\hline At3g57040 & Response regulator 9 (ARR9) & 79.2 & 42.2 & 70.6 & 25.8 & $0.5 \pm 0.1$ & $0.4 \pm 0.3$ \\
\hline At5g62920 & Response regulator 6 (ARR6) & 42.6 & 19.4 & 72.6 & 16.9 & $0.5 \pm 0.1$ & $0.2 \pm 0.2$ \\
\hline At4g16110 & Response regulator (similar to $A R R 2$ ) & 85.8 & 38.2 & 43.8 & 37.6 & $0.4 \pm 0.1$ & $0.9 \pm 0.2$ \\
\hline At1g67710 & Response regulator (ARRI1) & 53.3 & 20.3 & 53.3 & 3.6 & $0.4 \pm 0.1$ & $0.1 \pm 0.1$ \\
\hline At2g41510 & Cytokinin oxidase $(C K X 1)$ & 36.7 & 13.8 & 42.8 & 10.7 & $0.4 \pm 0.1$ & $0.2 \pm 0.2$ \\
\hline Atlg19050 & Response regulator 7 (ARR7) & 611.2 & 160.8 & 524.2 & 141.7 & $0.3 \pm 0.1$ & $0.3 \pm 0.3$ \\
\hline At3g63110 & Cytokinin synthase (IPT3) & 194.4 & 45.5 & 260.3 & 24.0 & $0.2 \pm 0.1$ & $0.1 \pm 0.4$ \\
\hline At5g05440 & Cytokinin-specific binding protein & 1171.6 & 259.4 & 979.9 & 280.5 & $0.2 \pm 0.1$ & $0.3 \pm 0.3$ \\
\hline At3g63440 & Cytokinin oxidase (CKXØ) & 364.6 & 36.5 & 336.6 & 9.4 & $0.1 \pm 0.1$ & $0.1 \pm 0.1$ \\
\hline
\end{tabular}

${ }^{a}$ Influenced by Plasmodiophora brassicae in infected and not inoculated plants of ecotype Col-0 at two timepoint after inoculation. All values are normalized to the expression level of not inoculated Col-0 plants at the corresponding timepoint. Mean values of expression levels of three independent experiments and the mean values of induction and standard deviations are given.

${ }^{\mathrm{b}}$ dag $=$ days after germination; dpi $=$ days postinfection.

${ }^{\mathrm{c}}(10 \mathrm{dpi} / 24 \mathrm{dag}) \pm \mathrm{SD}$ (standard deviation).

${ }^{\mathrm{d}}(23 \mathrm{dpi} / 37 \mathrm{dag}) \pm \mathrm{SD}$. 
Remarkably, one cytokinin receptor gene (CRE1/AHK4) was significantly upregulated, which could cause an increased sensitivity of the tissue toward cytokinin. Consistently, a higher expression level of the ARR5 gene, a cytokinin-sensitive reporter gene, was found. In spite of cytokinin production by the pathogen, cytokinin-regulated genes, with the exception of ARR5, were not generally upregulated. It could be that the transcript levels of primary cytokinin response genes are not enhanced in response to long-lasting changes in cytokinin concentrations or that the response is tissue-specific and does not occur in clubs.

Moreover, the microarray analyses pointed to $A t C K X$ genes as possible regulatory targets of the pathogen. The expression of two genes encoding cytokinin oxidases/dehydrogenases (AtCKX1 and $A t C K X 6)$, responsible for cytokinin degradation, was reduced. A third gene (AtCKX4) was slightly upregulated at the second timepoint of infection, but the expression level of this gene was near the detection limit of the method and specific expression was not detectable in experiments using promoterGUS lines (Fig. 6). Although, according to the microarray data, $A t C K X 1$ is also expressed at low levels, expression is focused to certain root tissues, such as root-branching points, and is therefore visible after GUS-staining of respective lines. Reduction of AtCKXI expression in P. brassicae-induced root galls might be due to the fact that lateral root formation was reduced. The downregulation of the cytokinin degradation capacity within colonized cells in combination with cytokinin production inside these cells by the pathogen could eventually turn colonized cells into a strongly dividing tissue by small amounts of pathogen-derived cytokinin.

Since whole roots were used, it might be possible that more subtle effects in specific areas of the root were not detected. The relative amounts of root tips in the overall tissue samples will clearly have an effect on the microarray data obtained. This is a general dilemma of this type of study. When the symp-

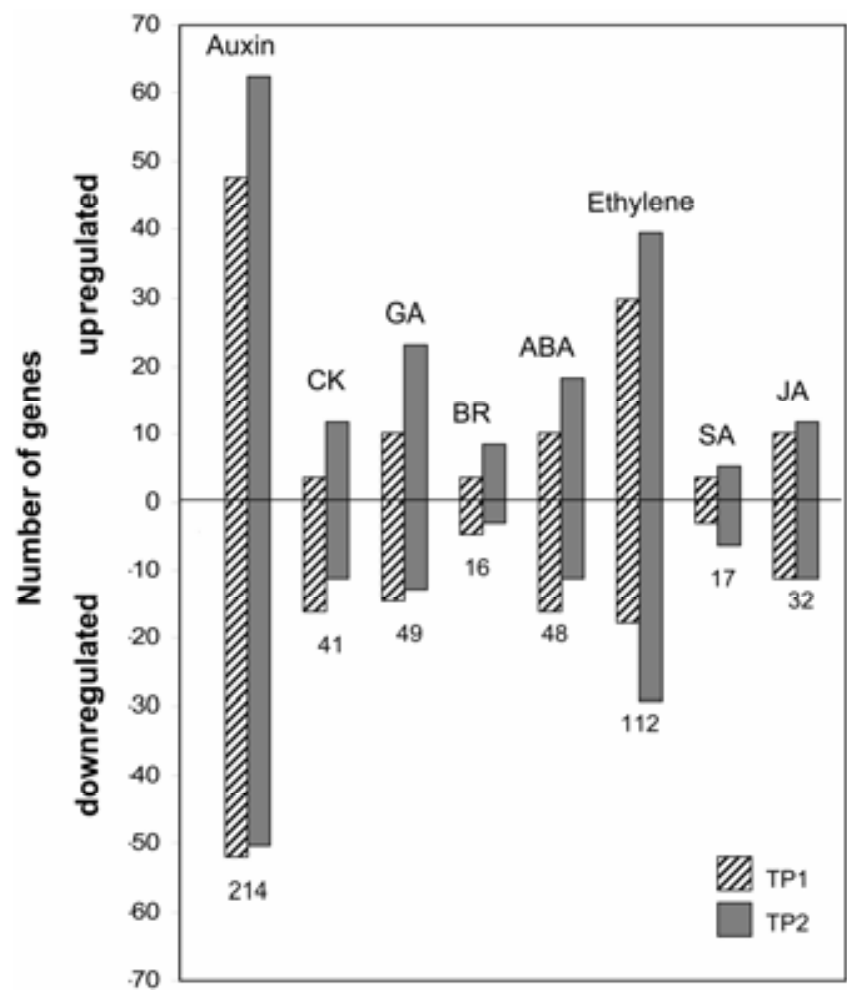

Fig. 4. Changes in hormone-related genes according to the MAPMAN classification. The number below the bars indicate total genes annotated in this category in MAPMAN. CK = cytokinin; GA = gibberellin; $\mathrm{BR}=$ brassinosteroid; $\mathrm{ABA}=$ abscisic acid; $\mathrm{SA}=$ salicylic acid; $\mathrm{JA}=$ jasmonic acid. toms caused by infection lead to a pronounced change in organ development, it may be difficult to identify cause and effect.

Two root-specific cytokinin oxidases, AtCKX1 and AtCKX6, are downregulated, which could be part of the strategy of the pathogen to enhance the effects of cytokinins in plasmodia-containing cells. The overproduction of $A t C K X 1$ and $A t C K X 3$ in the roots of $A$. thaliana induces an apparent resistance phenotype to $P$. brassicae, supporting the importance of the downregulation of cytokinin degradation during infection. In contrast, the overexpression of $A t C K X 2$ has only a limited effect on clubroot disease. Clearly, data have been previously presented that demonstrate a decrease of the cytokinin content on $A t C K X$-overexpressing transgenic plants in two different ways: i) by measuring the endogenous content and ii) by analyzing a cytokinin-sensitive reporter gene in the mutant background (Werner et al. 2003). The conclusion of a reduced cytokinin content in these plants is fully supported by additional analyses of gene expression by microarrays (Brenner et al. 2005). A reduction of the endogenous cytokinin content has been demonstrated in different tissues and in different developmental stages.

The subcellular compartmentation of different AtCKX proteins in Arabidopsis may be responsible for the different phenotypes seen in the different $A t C K X$-overexpressing lines. Enzymes $A t C K X 1$ and $A t C K X 3$ were localized in the vacuole, whereas $A t C K X 2$ is presumably localized in the apoplast of root cells, indicating an important role for subcellular compartmentation in cytokinin function (Werner et al. 2003). Schmülling and associates (2003) proposed that each cell during cell division produces its own cytokinin for its own exclusive use and that extracellular $A t C K X$ may serve as protectant from cytokinins derived from neighboring cells, preserving the cytokinin

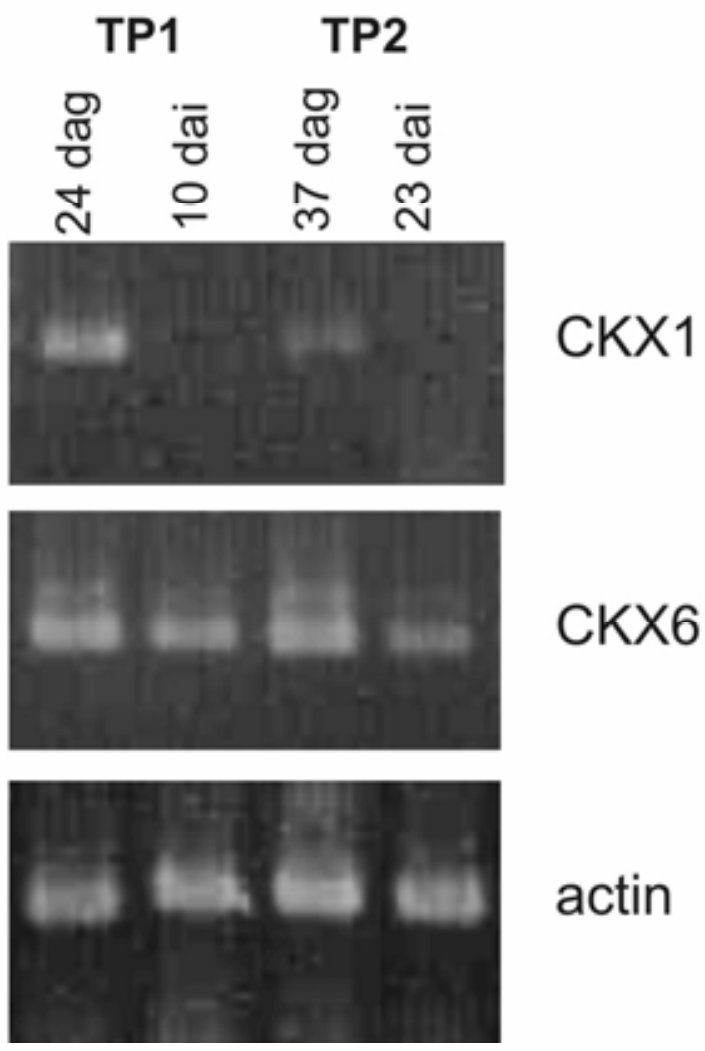

Fig. 5. Comparison of expression of $A t C K X 1$ and $A t C K X 6$ by reverse transcription-polymerase chain reaction in control (24 and 37 days after germination [dag]) and inoculated (10 and 23 days after inoculation [dai]) roots at early (TP1) and late (TP2) infection timepoints. Similar expression levels in all samples were shown by the amplification of actin 2 . The inoculated roots are from plants of the same age as the control roots. 
autonomy of each single cell. Vacuolar localization of $A t C K X$ might create a stronger intracellular sink for cytokinins. In accordance with this hypothesis, $P$. brassicae induces the root gall presumably from the inside of pericycle cells (Kobelt et al 2000). Therefore, the overexpression of intracellularly localized $A t C K X$ proteins may be more effective than the overexpression of the extracellular $A t C K X 2$.

In addition to the downregulation of $A t C K X$, several components of cytokinin signaling, such as $A H K 4 / C R E 1$ and ARR5, showed significantly altered expression patterns. This might, in turn, control downstream responses to cytokinin, such as alterations in the nutrient status and sink of the infected tissue.

In accordance with the hypothesis that the combined effects of auxin and cytokinin are causally involved in the pathogenesis of clubroot disease, microarray data and overexpression lines provided evidence that cytokinin is a crucial factor of gall development. The relevance of cytokinin for pathogenicity is highlighted by the resistance of $A t C K X$-overexpressing plants to $P$. brassicae. This finding might constitute a novel mechanism of disease resistance against $P$. brassicae. The limited cytokinin production rate of the pathogen may be compensated by downregulation of the cytokinin degradation capacity of the host cells. During further development of a club, the upregulation of nitrilases and the auxin-inducible $G H 3$ homologs point to the

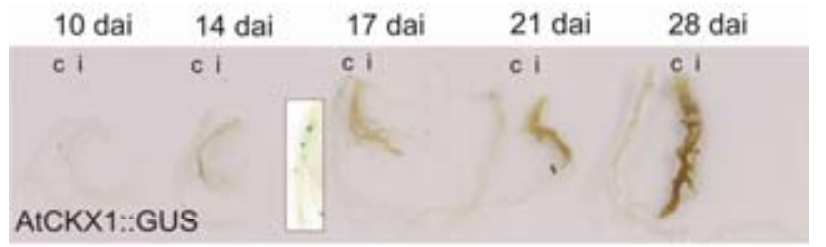

ci ci ci ci ci
AtCKX6::GUS
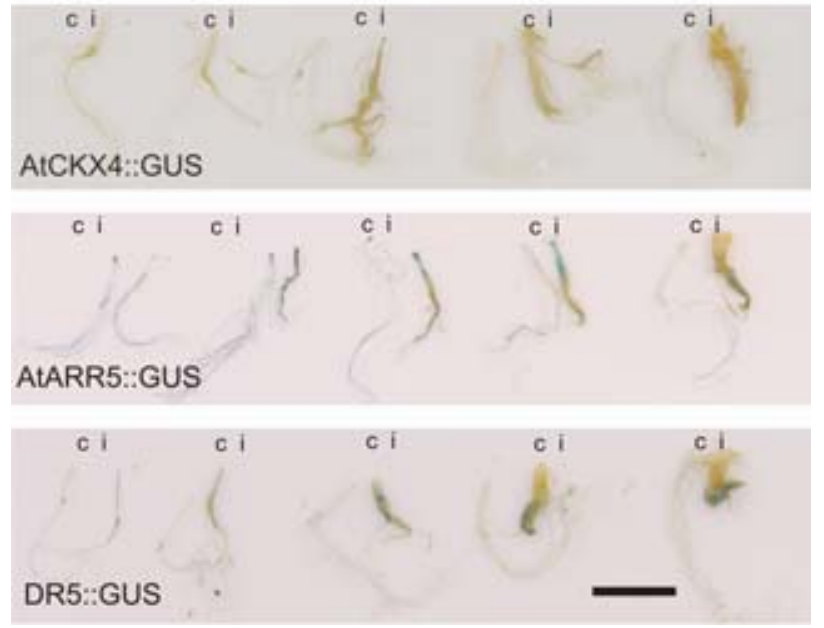

Fig. 6. Roots of the promoter::GUS lines for cytokinin oxidases $C K X 1:$ : GUS, CKX4::GUS, and CKX6::GUS differentially regulated according to the microarray experiment and, for comparison, cytokinin- (ARR5::GUS) and auxin (DR5::GUS)-responsive promoter:GUS lines were stained with 5-bromo-4-chloro-3-indolyl- $\beta$-D-glucuronide and were photographed at $10,14,17,21$, and 28 days (right) after inoculation with Plasmodiophora brassicae $(\mathrm{c}=$ control plants, $\mathrm{i}=$ inoculated plants). The $\beta$-glucuronidase staining at the beginning of the experiment was the same as for the first timepoint (data not shown). Bars represent $1 \mathrm{~cm}$. The brownish color of the infected roots is due to the age of the roots and develops concomitantly with gall size. Destaining with ethanol or acetone does not reduce the brown color. The inlet shows an enlarged control root of $C K X 1:: G U S$ to visualize the specific staining at root-branching points. crucial role of auxin homeostasis. Despite the importance of both phytohormones for club development, $P$. brassicae seems to be able to regulate a high number of other genes by a yetunknown mechanism during the early movement to the vascular cylinder and the colonization of the root cortex.
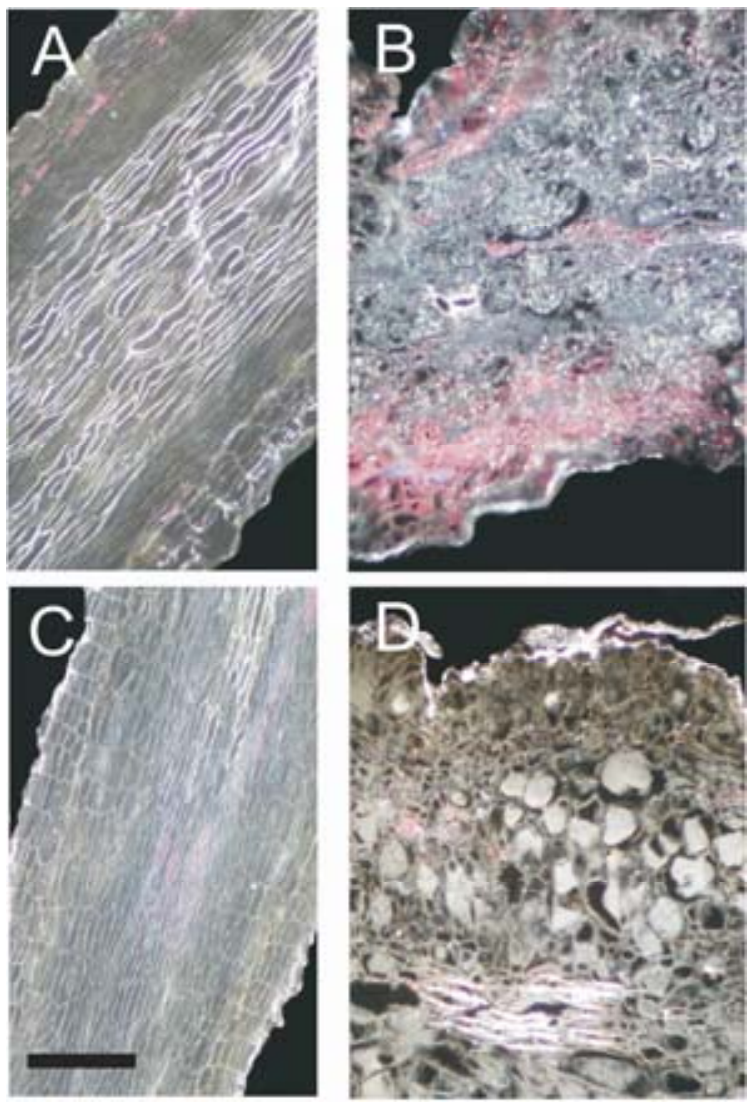

Fig. 7. Histochemical analysis of longitudinal root sections. A and B, Lines ARR5::GUS and $\mathbf{C}$ and D, CKX6::GUS stained with 5-bromo-4-chloro-3-indolyl- $\beta$-D-glucuronide 28 days after inoculation with Plasmodiophora brassicae ( $\mathrm{B}$ and $\mathrm{D}$ ) and corresponding control roots (A and $\mathrm{C})$. Bars represent $100 \mu \mathrm{m}$. The pictures were taken under dark-field conditions for better contrast; therefore, the $\beta$-glucuronidase staining is visible as magenta stain.

Table 5. Interaction of overexpression lines of $A t C K X 1, A t C K X 2, A t C K X 3$, and ecotype Col-0 with different isolates of Plasmodiophora brassicae and different inoculation pressure ${ }^{\mathrm{a}}$

\begin{tabular}{|c|c|c|c|}
\hline Line & Isolate & Disease index & $\mathbf{R}_{\mathbf{i}} / \mathbf{R}_{\mathbf{n i}}$ \\
\hline Col-0 & $\mathrm{e}_{\mathrm{H}}$ & 99.2 & $4.78 \pm 0.86$ \\
\hline Col-0 & $1 \mathrm{CK}$ & 100.0 & $4.19 \pm 0.83$ \\
\hline Col-0 & $\mathrm{k}_{1}$ & 96.9 & $2.58 \pm 0.60$ \\
\hline Col-0 & $\mathrm{e}_{2}$ & 91.4 & $7.70 \pm 0.94$ \\
\hline $35 S: \because A t C K X 1$ & $\mathrm{e}_{\mathrm{H}}$ & $31.03^{(\mathrm{s} .)}$ & $1.15 \pm 0.28$ \\
\hline $35 S: \because A t C K X 1$ & $1 \mathrm{CK}$ & $50.6^{(\mathrm{s} .)}$ & $0.66 \pm 0.31$ \\
\hline $35 S: \because A t C K X 1$ & $\mathrm{k}_{1}$ & $40.8^{(\mathrm{s} .)}$ & $0.99 \pm 0.23$ \\
\hline $35 S: \because A t C K X 1$ & $e_{2}$ & $62.5^{\text {(s.) }}$ & $1.29 \pm 0.43$ \\
\hline $35 S: \because A t C K X 2$ & $\mathrm{e}_{\mathrm{H}}$ & $90.07^{\text {(n.s.) }}$ & $2.61 \pm 0.80$ \\
\hline $35 S: \because A t C K X 2$ & $1 \mathrm{CK}$ & $100.0^{\text {(n.s.) }}$ & $1.97 \pm 0.53$ \\
\hline $35 S: \because A t C K X 2$ & $\mathrm{k}_{1}$ & $77.9^{\text {(s.) }}$ & $1.36 \pm 0.45$ \\
\hline $35 S: A t C K X 2$ & $\mathrm{e}_{2}$ & $83.3^{\text {(n.s.) }}$ & $3.39 \pm 0.82$ \\
\hline $35 S: \because A t C K X 3$ & $\mathrm{e}_{\mathrm{H}}$ & $61.6^{(\mathrm{s} .)}$ & $1.23 \pm 0.10$ \\
\hline $35 S:: A t C K X 3$ & $1 \mathrm{CK}$ & $71.0^{(\mathrm{s} .)}$ & $1.81 \pm 0.65$ \\
\hline $35 S: \because A t C K X 3$ & $\mathrm{k}_{1}$ & $79.0^{(\mathrm{s} .)}$ & $1.77 \pm 0.51$ \\
\hline $35 S: \because A t C K X 3$ & $e_{2}$ & $68.8^{(\mathrm{s} .)}$ & $1.83 \pm 0.49$ \\
\hline
\end{tabular}

a The disease indices (DI) and the mean values and standard deviations of the root index $\left(\mathrm{R}_{\mathrm{i}} / \mathrm{R}_{\mathrm{ni}}\right)$ of the different host-pathogen combinations are given. ${ }^{\text {(s.) }}$ or ${ }^{\text {(n.s.) }}$ indicate a significant or not significant difference $(\alpha=$ 0.05) compared with Columbia, using the same isolate and infection pressure calculated by Kruskal-Wallis analysis and mean rank comparison. 


\section{MATERIALS AND METHODS}

Plant and pathogen material.

Plant material. The ecotype Col-0 of Arabidopsis thaliana was originally provided by Nottingham Arabidopsis Stock Cen-
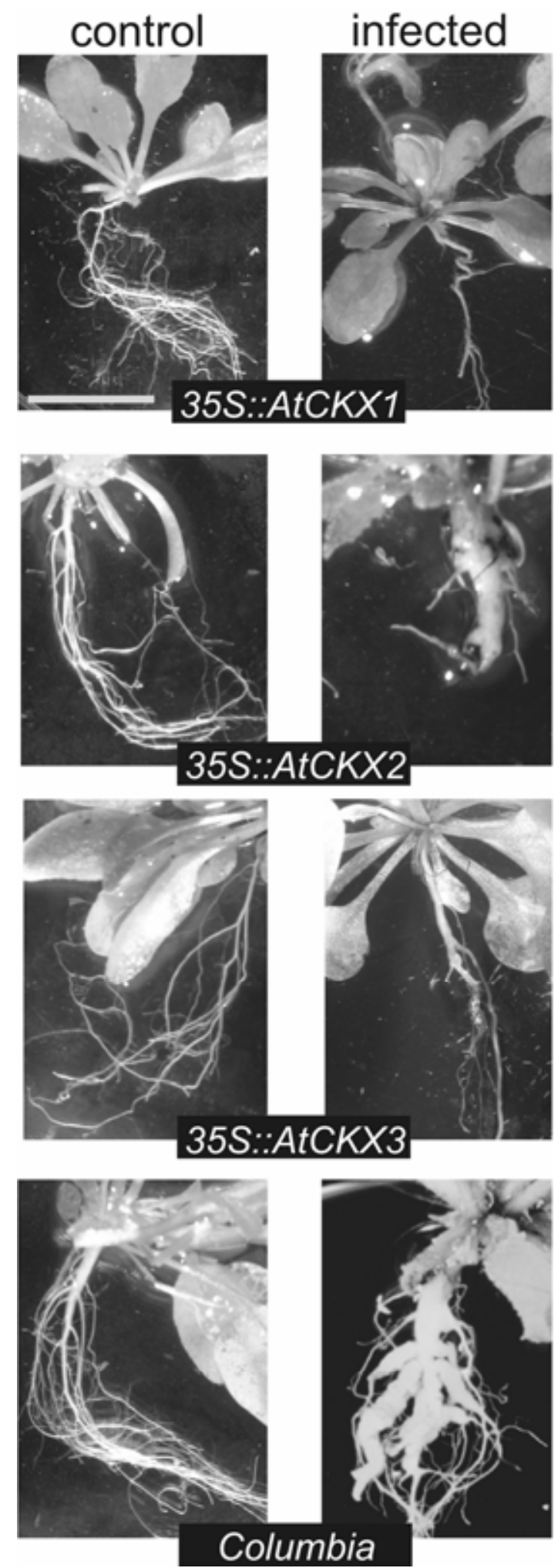

Fig. 8. Representative examples of infected plants of $35 S:: A t C K X 1$, 35S::AtCKX2, and 35S::AtCKX3 28 days after infection with the Plasmodiophora brassicae isolate ' $\mathrm{e}_{\mathrm{H}}$ ' in comparison with roots of ecotype Columbia. All plants are shown at the same magnification. The bar represents $1 \mathrm{~cm}$. The differences in rosette size are due to the fact that some of the $35 S:: A t C K X$-overexpressing plants have a dwarf phenotype. tre (Nottingham, U.K.). Brassica rapa L. subsp. pekinensis cv. Granaat (ECD-05) was used for propagation of all isolates of $P$. brassicae. The transgenic lines overproducing cytokinin oxidases/dehydrogenases (35S::AtCKX1, 35S::AtCKX2, 35S::At$C K X 3)$ and the transgenic lines carrying promotor-GUS fusions of the different AtCKX genes (CKX1::GUS, CKX2::GUS, CKX3::GUS, CKX4::GUS, CKX5::GUS, CKX6::GUS) as well as line ARR5::GUS/CKX1::GUS were described by Werner and associates (2003). The line carrying the GUS gene under control of an auxin-responsive promotor (DR5::GUS) and the line carrying the $G U S$ gene under control of a cytokinin-responsive promotor (ARR5::GUS) were provided by T. Guilfoyle (University of Missouri, Columbia, MO, U.S.A.) and J. Kieber (University of North Carolina, Chapel, Hill, NC, U.S.A.), respectively.

Pathogen material. P. brassicae isolates ' $\mathrm{e}_{\mathrm{H}}$ ', ' $\mathrm{e}_{3}$ ', ' $\mathrm{e}_{2}$ ', and ' $k_{2}$ ' were described by Fähling and associates (2003) and Graf and associates (2004). The isolate ' $1-\mathrm{CK}$ ' is a single-spore isolate produced at INRA (Institut National de Recherche Agricultural-Station d`Amélioration des Plantes, Le Rheu Cedex, France). Clubroot galls of all isolates were stored at $-20^{\circ} \mathrm{C}$ until required. Resting spores were extracted by homogenizing mature clubroot galls of Chinese cabbage, followed by filtering through gauze $(25 \mu \mathrm{m}$ pore width) and two centrifugation steps $(2,500 \times g, 10 \mathrm{~min})$ (Sacristán and Hoffmann 1979).

For propagation of $P$. brassicae isolates $B$. rapa $\mathrm{cv}$. Granaat plants were inoculated with $4 \mathrm{ml}$ of spore suspension $\left(10^{7}\right.$ spores $/ \mathrm{ml}) 4$ days after sowing and were cultivated for 8 weeks in the greenhouse.

\section{AtARR5::GUS}
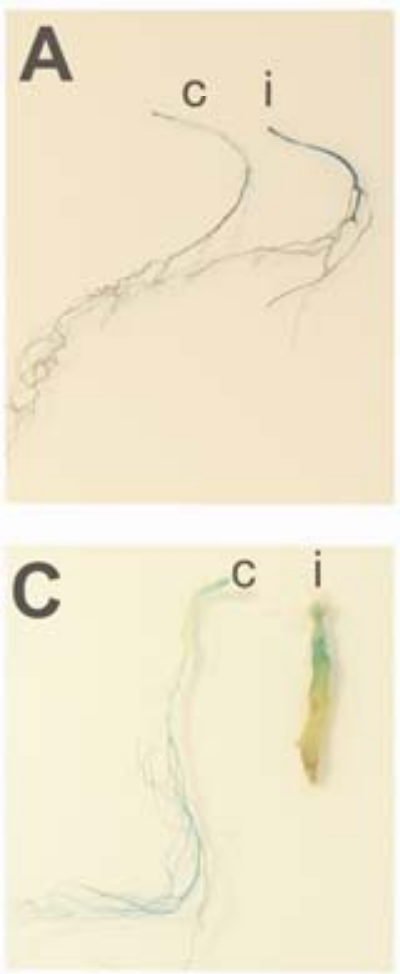

\section{S::AtCKX1 AtARR5::GUS}
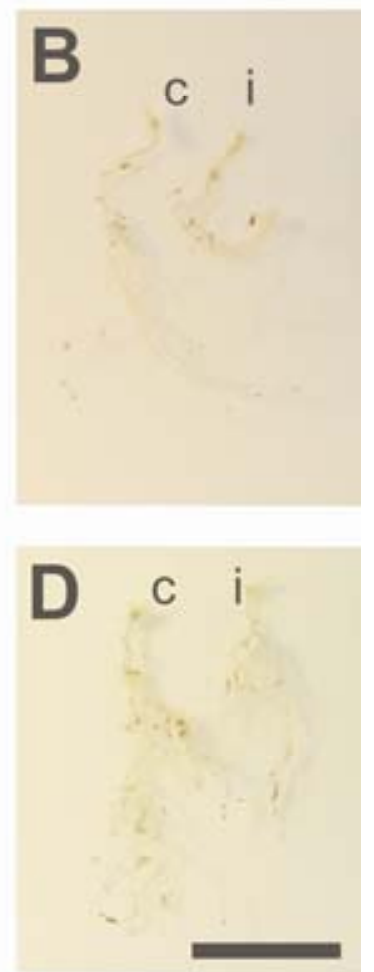

Fig. 9. The expression of the cytokinin-responsive promoter::GUS construct AtARR $:: G U S$ was analyzed in the genetic background of ecotype Columbia and of the CKX1-overproducing line 35S::CKX1. Roots were stained with 5bromo-4-chloro-3-indolyl- $\beta$-D-glucuronide and photographed at $\mathbf{A}$ and $\mathbf{B}$, 14, and $\mathbf{C}$ and $\mathbf{D}, 21$ days after inoculation with Plasmodiophora brassicae $(\mathrm{c}=$ control plants, $\mathrm{i}=$ inoculated plants $)$. Due to infection, the root systems of the inoculated $35 S: \because C K X 1$ plants are slightly reduced, but no clearly clubroot symptoms are visible. Bar represents $1 \mathrm{~cm}$. 
Cultivation and inoculation of plants. Cultivation and inoculation conditions of plants were performed according to Kobelt and associates (2000). Plants (14-day-old) cultivated in a controlled environment $\left(21 \pm 1^{\circ} \mathrm{C}, 16 \mathrm{~h}\right.$ of light, $100 \mu \mathrm{mol}$ photons $\mathrm{s}^{-1} \mathrm{~m}^{-2}$ ) were inoculated by injecting the soil around each plant with $2 \mathrm{ml}$ of a resting spore suspension of the pathogen with a standard concentration of $10^{6}$ spores per milliliter. Disease symptoms were assessed 28 dai, using a scale consisting of five classes and by estimating the $\mathrm{R}_{\mathrm{i}} / \mathrm{R}_{\mathrm{ni}}$ indices according to Siemens and associates (2002). Disease symptoms were assessed using a scale consisting of five classes according to Klewer and associates (2001): $0=$ no symptoms, $1=$ very small clubs, mainly on lateral roots that do not impair the main root, $2=$ small clubs covering the main root and a few lateral roots, 3 = medium-sized to bigger clubs, also including the main root, plant growth might be impaired, $4=$ severe clubs in lateral, main root or rosette, fine roots completely destroyed, plant growth is affected. Disease index was calculated using the five-grade scale according to the formula DI $=\left(1 n_{1}+2 n_{2}+\right.$ $\left.3 n_{3}+4 n_{4}\right) \times 100 / 4 N_{t}$, where $n_{1}$ to $n_{4}$ represent the number of plants in the indicated class and $\mathrm{N}_{\mathrm{t}}$ the total number of plants tested. For each isolate and line combination, at least $140 \mathrm{Arabi}$ dopsis plants were analyzed. These data were analyzed with the Kruskal-Wallis test, and subsequently, the mean rank differences were compared (Siegel and Castellan 1988).

For quantitative estimation, the plants were cut at the top of the hypocotyl into shoots and roots. The infected roots were measured as galls, ignoring occasional remaining noninfected lateral roots. Root fresh weight was used to calculate the root index according to Siemens and associates (2002). For each isolate and line combination, at least 35 Arabidopsis plants were analyzed and compared by Student $t$-test.

\section{RNA preparation, cRNA synthesis, and microarray hybridization.}

RNA preparation, cRNA synthesis, and microarray Affymetrix GeneChip array hybridization was performed at the John Innes Genome Laboratory, using the outlined modifications of protocols described in the Affymetrix expression analysis technical manual II (Affymetrix, Santa Clara, CA, U.S.A.).

At two timepoints after inoculation, roots of inoculated plants (10 and 23 dai) and roots of the corresponding noninoculated plants ( 24 and $37 \mathrm{dag}$ ) were harvested. Soil residue was carefully removed from roots using brushes, and the roots were immediately frozen in liquid nitrogen and were grounded with mortar and pestle. Briefly, total RNA was extracted from three independent experiments by the RNeasy plant mini kit (Qiagen, Venlo, The Netherlands) according to the manufacturer's instructions. RNA samples were further cleaned using Qiagen RNeasy mini-columns, and their quality was assessed by running $1 \mu \mathrm{l}$ of each RNA sample on Agilent RNA6000nano LabChips (2100 Bioanalyzer Version A.01.20 SI211; Agilent Technology, Palo Alto, CA, U.S.A.). First-strand cDNA synthesis was performed according to the Affymetrix manual II, using 10 $\mu \mathrm{g}$ of total RNA. Second-strand cDNA synthesis was performed with minor modifications to the Affymetrix manual II. cDNA termini were not blunt-ended and the reaction was not terminated using EDTA. Instead, double-stranded cDNA products were immediately purified following the "Cleanup of DoubleStranded cDNA" protocol (Affymetrix manual II). cDNA was resuspended in $22 \mu \mathrm{l}$ of RNAse free water.

cRNA preparation was performed with minor modifications to the Affymetrix manual II. cDNA $(11 \mu \mathrm{l})$ was used as a template to produce biotinylated cRNA, using half the recommended volumes of the ENZO bioarray high yield RNA transcript labeling kit (ENZO Life Sciences, Farmingdale, NY, U.S.A.). Labeled cRNAs were purified following the "Cleanup and Quantification of Biotin-Labeled cRNA" protocol (Affymetrix manual II). cRNA quality was assessed on Agilent RNA6000nano LabChips (2100 Bioanalyzer Version A.01.20 SI211, Agilent Technology). cRNA $(20 \mu \mathrm{g})$ was fragmented according to the Affymetrix manual II.

High-density oligonucleotide arrays containing probes of more than 22,000 different Arabidopsis genes (Arabidopsis ATH1 arrays; Affymetrix) were used for gene expression detection. Hybridization overnight at $45^{\circ} \mathrm{C}$ and $60 \mathrm{rpm}$ (Hybridization Oven 640), washing and staining (GeneChip Fluidics Station 450, using the EukGEws2_450 Antibody amplification protocol), and scanning (GeneArray 2500) was carried out according to the Affymetrix manual II.

Microarray suite 5.0 (Affymetrix) was used for image analysis and to determine probe signal levels. The average intensity of all probe sets was used for normalization and scaled to 100 in the absolute analysis for each probe array. For each microarray, overall intensity normalization for the entire probe sets was performed using Affymetrix Microarray Suite 5.0. Using the GeneChip Suite 5.0 default parameters, the detection $P$ value and the signal value were calculated for each probe set from each independent timepoint and condition. The detection $P$-value generated by this analysis allowed us to determine whether a transcript is reliably detected (present, $P$-value < 0.04 ), and the signal value assigns a relative measure of abundance to the transcript. The data were then passed through a quality filter using Access (Microsoft, Redmond, WA, U.S.A.), through which transcripts were selected for further analyses according to the following ad hoc criteria. A significantly expressed transcript must have been significantly expressed in at least two samples obtained under the same condition ( $\mathrm{P}$ for present, detection $P$-value $<0.04)$. Note that low-abundance transcripts may actually encode important cellular proteins, even if statistical analyses define these as absent (A). To monitor and assess different genes from three independent samples, expression induction (ratio $>2 \times$, ratio $>20 \times$ ) or repression (ratio $<0.5 \times$, ratio $<0.05 \times$ ) were calculated as mean values and standard deviation of the ratios of expression values of a particular sample (10 and 23 dai) and its corresponding control sample (24 and 37 dag) (inoculated versus control) using Excel (Microsoft, Redmond, WA, U.S.A.). Annotation of transcripts presented in the tables was done by using the Affymetrix probe set IDs for the respective genes and annotation and AGI numbers from the Salk Institute genomic analysis laboratory database SIGnAL were retrieved. The annotation of highly regulated genes was constantly updated using TIGR and TAIR databases.

\section{Data analysis using the MAPMAN software.}

Ratios of control to infected roots were calculated for each timepoint (TP1, TP2) for all values, and the values were converted to $\log _{2}$ in Excel files. For the data import into MAPMAN, the protocol given in the instructions was followed.

\section{RT-PCR.}

Total RNA was prepared using the RNeasy kit (Qiagen). Fresh weight of control and infected root material $(100 \mathrm{mg})$ was harvested, washed thoroughly, dried between filter paper and homogenized in $450 \mu \mathrm{l}$ of extraction buffer according to the manufacturer's instructions. To minimize contamination with genomic DNA, RNA was digested with RNase-free DNase (1 U $\left.\mu^{-1}\right)$ (Stratagene, La Jolla, CA, U.S.A.). First-strand cDNA was prepared from total RNA using M-MLV reverse transcriptase (Invitrogen, Carlsbad, CA, U.S.A.).

Amplification of partial AtCKX1 and AtCKX6 cDNA fragments by PCR was performed using the following primers: sense primer AtCKX1, 5'-GGCAATTCTACATCCAAGGTC AG-3'; antisense primer AtCKX1, 5'-CAAGCCCGCCAAGAA 
CACT-3'; sense primer AtCKX6, 5'-ATTTGGAAACATACTA ACGGATACAAG; and antisense primer AtCKX6, 5'-TACTAC ATATATGGATACGCATCATCG. These sequences are perfect match primers corresponding to a nonhomologous region to other $A t C K X$ genes in the coding region of $A t C K X 1$, resulting in a 430-bp amplificate, and to a sequence with low homology in the coding sequence (sense) as well as the $3^{\prime}$ untranslated region (antisense) of $A t C K X 6$, resulting in a 496-bp amplificate, respectively. As control, all cDNA samples were amplified with actin 2 (At3g18780) primers with the following sequences: sense primer actin, 5'-GAAGATTAAGGTCGTTG CACCACCTG; and antisense primer actin, 5'-ATTAACATTG CAAAGAGTTTCAAGGT. PCR was performed according to standard procedures, using the following program for actin amplification. Initial denaturation at $94^{\circ} \mathrm{C}$ for $5 \mathrm{~min}$, followed by 40 cycles of $94^{\circ} \mathrm{C}$ for $30 \mathrm{~s}, 62^{\circ} \mathrm{C}$ for $60 \mathrm{~s}, 72^{\circ} \mathrm{C}$ for $60 \mathrm{~s}$, and final elongation at $72^{\circ} \mathrm{C}$ for $5 \mathrm{~min}$. The same program was used for the amplification of $A t C K X 1$ and $A t C K X 6$, but the annealing temperature was $54^{\circ} \mathrm{C}$.

The PCR fragments were excised from the gel, were eluted with the StrataPrepDNA gel extraction kit (Stratagene, La Jolla, CA, U.S.A.), and were directly submitted to sequencing (SeqLab, Göttingen, Germany). Sequence alignments were performed using BLAST (Altschul et al. 1997). All other standard molecular methods were performed according to Sambrook and associates (1989).

\section{GUS staining.}

Histochemical GUS staining was performed by incubating control and $P$. brassicae-infected plants with their roots in a solution containing $0.5 \mathrm{mg}$ of 5 -bromo-4-chloro-3-indolyl- $\beta$-Dglucuronide per milliliter dissolved in $0.1 \mathrm{M}$ phosphate buffer, pH 7.4, containing $10 \mathrm{mM} \mathrm{Na}_{2}$ EDTA, $0.5 \mathrm{mM} \mathrm{K}_{3}\left[\mathrm{Fe}(\mathrm{CN})_{6}\right], 0.5$ $\mathrm{mM} \mathrm{K}_{4}\left[\mathrm{Fe}(\mathrm{CN})_{6}\right]$, and $0.5 \%$ (wt/vol) Triton-X-100 (Jefferson 1987). The incubation was stopped by washing the roots in phosphate buffer, $\mathrm{pH} 7.4$, without substrate and storing the roots in $70 \%(\mathrm{vol} / \mathrm{vol})$ ethanol. Stained roots were embedded in glycolmethacrylate (Technovit 7100; Heraeus-Kulzer, Wehrheim, Germany) according to Kobelt and associates (2000), and sections of 5 to $10 \mu \mathrm{m}$ thickness were analyzed in dark field or in bright field after staining with methylene blue and basic fuchsin.

\section{ACKNOWLEDGMENTS}

We thank J. Hadfield at the John Innes Genome Laboratory for array hybridization. The transgenic line ARR5::GUS was kindly supplied by J. Kieber, University of North Carolina, and DR5::GUS plants were obtained from T. Guilfoyle, University of Missouri. We would further like to thank S. Heinze, J. Rieckhoff, and A. Nöh for excellent technical assistance. Research at the Sainsbury Laboratory is funded by the Gatsby Charitable Foundation.

\section{LITERATURE CITED}

Altschul, S. F., Madden, T. L., Schäffer, A. A., Zhang, J., Zhang, Z., Miller, W., and Lipman, D. J. 1997. Gapped BLAST and PSI-BLAST: A new generation of protein database search Programs. Nucleic Acid Res. 25:3389-3402.

Arbeiter, A., Fähling, M., Graf, H., Sacristán, M.D., and Siemens, J. 2002. Resistance of Arabidopsis thaliana to the obligate biotrophic parasite Plasmodiophora brassicae. Plant Protect. Sci. 38:519-522.

Braselton, J. P. 1995. Current status of the Plasmodiophorids. Crit. Rev. Microbiol. 21:263-275.

Brenner, W.G., Romanov, G.A., Köllmer, I., Bürkle, L., Schmülling, T. 2005. Immediate-early and delayed cytokinin response genes of Arabidopsis thaliana identified by genome-wide expression profiling reveal novel cytokinin-sensitive processes and suggest cytokinin action through transcriptional cascades. Plant J. 44:314-333.

Butcher, D. N., El-Tigani, S., and Ingram, D. S. 1974. The role of indole glucosinolates in the clubroot disease of the Cruciferae. Physiol. Plant Pathol. 4:127-141.
Butcher, D. N., Chamberlain, K., Rausch, T., and Searle, L. M. 1984. Changes in indole metabolism during the development of clubroot symptoms in Brassicas. In: Biochemical aspects of synthetic and naturally occurring plant growth regulators, British Plant Growth Regulator Group, Monograph 11:91-101.

Chen, J.-G., Shimomura, S., Sitbon, F., Sandberg, G., and Jones, A. M. 2001a. The role of auxin-binding protein 1 in the expansion of tobacco leaf cells. Plant J. 28:607-617.

Chen, J.-G., Ullah, H., Young, J. C., Sussman, M. R., and Jones, A. M. 2001b. ABP1 is required for organized cell elongation and division in Arabidopsis embryogenesis. Genes Dev. 15:902-911.

Crisp, P., Crute, I. R., Sutherland, R. A., Angell, S. M., Bloor, K., Burgess, H., and Gordon, P. L. 1989. The exploitation of genetic resources of Brassica oleracea in breeding for resistance to clubroot Plasmodiophora brassicae. Euphytica 42:215-226.

Czechowski, T., Bari, R. P., Stitt, M., Scheible, W.-R., Udvardi, M. K. 2004. Real-time RT-PCR profiling of over 1400 Arabidopsis transcription factors: Unprecedented sensitivity reveals novel root- and shootspecific genes. Plant J. 38:366-379.

Czechowski, T., Stitt, M., Altmann, T., Udvardi, M. K., Scheible, W.-R. 2005. Genome-wide identification and testing of superior reference genes for transcript normalization in Arabidopsis. Plant Physiol. 139:517.

Dekhuijzen, H. M. 1981. The occurrence of free and bound cytokinins in plasmodia of Plasmodiophora brassicae isolated from tissue cultures of clubroots. Plant Cell Rep. 1:18-20.

Dekhuijzen, H. M., and Overeem, J. C. 1971. The role of cytokinins in clubroot formation. Physiol. Plant Pathol. 1:151-161.

Devos, S., Vissenberg, K., Verbelen, J.-P., and Prinsen, E. 2005. Infection of Chinese cabbage by Plasmodiophora brassicae leads to a stimulation of plant growth: Impacts on cell wall metabolism and hormonal balance. New Phytol. 166:241-250.

Dharmasiri, N., Dharmasiri, S., and Estelle, M. 2005. The F-box protein TIR1 is an auxin receptor. Nature 435:441-445.

Fähling, M., Graf, H., and Siemens, J. 2003. Pathotype-separation of Plasmodiophora brassicae by the host plant. J. Phytopath. 151:425-430.

Fuchs, H., and Sacristán, M. D. 1996. Identification of a gene in Arabidopsis thaliana controlling resistance to clubroot (Plasmodiophora brassicae) and characterization of the resistance response. Mol. PlantMicrobe Interact. 9:91-97.

Graf, H., Fähling, M., and Siemens, J. 2004. Chromosome polymorphism of the obligate biotrophic parasite Plasmodiophora brassicae. J. Phytopathol. 152:86-91.

Grsic, S., Kirchheim, B., Pieper, K., Fritsch, M., Hilgenberg, W., and Ludwig-Müller, J. 1999. Auxin biosynthesis in clubroot diseased Chinese cabbage plants and induction by jasmonic acid. Physiol. Plant. 105:521-531.

Grsic-Rausch, S., Kobelt, P., Siemens, J., Bischoff, M., and LudwigMüller, J. 2000. Expression and localization of nitrilase during symptom development of the clubroot disease in Arabidopsis thaliana. Plant Physiol. 122:369-378.

Holland, M. J. 2002. Transcript abundance in yeast varies over six orders of magnitude. J. Biol. Chem. 277:14363-14366.

Ingram, D. S., and Tommerup, I. C. 1972. The life history of Plasmodiophora brassicae Woron. Proc. Royal Soc. Lond. B 180:103-112.

Ito, S., Tanaka, S., Miyanaga, C., Takabayaski, S., Yano, S., and KameyaIwaki, M. 1996. Constitutive and inducible proteins in the root of Chinese cabbage infected with Plasmodiophora brassicae. J. Phytopathol. 144:89-95.

Ito, S., Ichinose, H., Yanagi, C., Tanaka, S., Kameya-Iwaki, M., and Kishi, F. 1999. Identification of an in planta-induced mRNA of Plasmodiophora brassicae. J. Phytopathol. 147:79-82.

Jefferson, R. A. 1987. Assaying chimeric genes in plants: The GUS gene fusion system. Plant Mol. Biol. Rep. 5:387-405.

Kepinski, S., and Leyser, O. 2005. The Arabidopsis F-box protein TIR1 is an auxin receptor. Nature 435:446-451.

Klewer, A., Luerßen, H., Graf, H., Siemens, J. 2001. Restriction Fragment Length Polymorphism markers to characterize Plasmodiophora brassicae single-spore isolates with different virulence patterns. J. Phytopathol. 149:121-127.

Kobelt, P., Siemens, J., and Sacristán, M. D. 2000 Histological characterisation of the incompatible interaction between Arabidopsis thaliana and the obligate biotrophic pathogen Plasmodiophora brassicae. Mycol. Res. 104:220-225.

Leyser, H. M. O., Lincoln, C. A., Timpte, C., Lammer, D., Turner, J., and Estelle, M. 1993. Arabidopsis auxin-resistance gene AXRl encodes a protein related to ubiquitin-activating enzyme-E1. Nature 364:161-164.

Ludwig-Müller, J. 1999. Plasmodiophora brassicae, the causal agent of clubroot disease: A review on molecular and biochemical events in pathogenesis. Zeitschr. Pflanzenkr. Pflanzenschutz 106:109-127. 
Ludwig-Müller, J., Bendel, U., Thermann, P., Ruppel, M., Epstein, E., and Hilgenberg, W. 1993. Concentrations of indole-3-acetic acid in plants of tolerant and susceptible varieties of Chinese cabbage infected with Plasmodiophora brassicae Woron. New Phytol. 125:763-769.

Ludwig-Müller, J., Thermann, P., Pieper, K., and Hilgenberg, W. 1994. Peroxidase and chitinase isoenzyme activities during root infection of Chinese cabbage with Plasmodiophora brassicae Woron. Physiol. Plant. 90:661-670.

Ludwig-Müller, J., Epstein, E., and Hilgenberg, W. 1996. Auxin-conjugate hydrolysis in Chinese cabbage: Characterization of an amidohydrolase and its role during the clubroot disease. Physiol. Plant 97:627-634

Ludwig-Müller, J., Pieper, K., Ruppel, M., Cohen, J. D., Epstein, E., Kiddle, G., and Bennett, R. 1999. Indole glucosinolate and auxin biosynthesis in Arabidopsis thaliana L. glucosinolate mutants and the development of the clubroot disease. Planta 208:409-419.

Mithen, R., and Magrath, R. 1992. A contribution to the life history of Plasmodiophora brassicae: Secondary plasmodia development in root galls of Arabidopsis thaliana. Mycol. Res. 96:877-885.

Müller, P., and Hilgenberg, W. 1986. Isomers of zeatin and zeatin riboside in clubroot tissue: Evidence for trans-zeatin biosynthesis by Plasmodiophora brassicae. Physiol. Plant. 66:245-250.

Neuhaus, K., Grsic-Rausch, S., Sauerteig, S., and Ludwig-Müller, J. 2000. Arabidopsis plants transformed with nitrilase 1 or 2 in antisense direction are delayed in clubroot development. J. Plant Physiol. 156:756-761.

Panstruga, R. 2003. Establishing compatibility between plants and obligate biotrophic pathogens. Curr. Opin. Plant Biol. 6:320-326.

Rausch, T., Butcher, D. N., and Hilgenberg, W. 1981. Nitrilase activity in clubroot diseased plants. Physiol. Plant. 52:467-470.

Rausch, T., Butcher, D. N., and Hilgenberg, W. 1983. Indole-3-methylglucosinolate biosynthesis and metabolism in clubroot diseased plants. Physiol. Plant. 58:93-100.

Sacristán, M. D., and Hoffmann, F. 1979. Direct infection of embryogenic tissue cultures of haploid Brassica napus with resting spores of Plasmodiophora brassicae. Theor. Appl. Genet. 54:129-132.

Sambrook, J., Fritsch, E. F., and Maniatis, T. 1989. Molecular Cloning: A Laboratory Manual. Cold Spring Harbor Laboratory Press, Cold Spring Harbor, NY, U.S.A.

Schmülling, T., Werner, T., Riefler, M., Krupkova, E., and Bartina y Manns, I. 2003. Structure and function of cytokinin oxidase/ dehydrogenase genes of maize, rice, Arabidopsis and other species. J. Plant Res. 116:241-252.

Schuller, A., and Ludwig-Müller, J. 2002. Isolation of differentially expressed genes involved in clubroot disease. Plant Protect. Sci. 38:483486.

Searle, L. M., Chamberlain, K., Rausch, T., and Butcher, D. N. 1982. The conversion of 3 -indolemethylglucosinolate to 3 -indoleacetonitrile by myrosinase and its relevance to the clubroot disease of the cruciferae. J. Exp. Bot. 33:935-942.
Siegel, S., and Castellan, N. J. 1988. Nonparametric statistics for the behavioral sciences. McGraw-Hill Book Company, New York.

Siemens, J., Nagel, M., Ludwig-Müller, J., and Sacristán, M. D. 2002. The interaction of Plasmodiophora brassicae and Arabidopsis thaliana: $\mathrm{Pa}$ rameters for disease quantification and screening of mutant lines. J. Phytopath. 150:592-605.

Siemens, J., Keller, I., Sarx, J., Kunz, S., Schuller, A., Nagel, W., Schmülling, T., Parniske, M., and Ludwig-Müller, J. Transcriptome analysis of Arabidopsis thaliana clubroots. Acta Hort., in press.

Staswick, P. E., Tiryaki, I., and Rowe, M. L. 2002. Jasmonate response locus JARI and several related Arabidopsis genes encode enzymes of the firefly luciferase superfamily that show activity on jasmonic, salicylic and indole-3-acetic acids in an assay for adenylation. Plant Cell 14:1405-1415.

Staswick, P. E., Serban, B., Rowe, M., Tiryaki, I., Maldonado, M. T., Maldonado, M. C., and Suza, W. 2005. Characterization of an Arabidopsis enzyme family that conjugates amino acids to indole-3-acetic acid. Plant Cell 17:616-627.

Steffens, B., Feckler, C., Palme, K., Christian, M., Böttger, M., and Lüthen, H. 2001. The auxin signal for protoplast swelling is perceived by extracellular ABP1. Plant J. 27:591-599.

Thimm, O., Blaesing, O., Gibon, Y., Nagel, A., Meyer, S., Krueger, P., Selbig, J., Mueller, L.A., Rhee, S.Y. and Stitt, M. 2004. MAPMAN: A user-driven tool to display genomics data sets onto diagrams of metabolic pathways and other biological processes. Plant J. 37:914-939.

Werner, T., Motyka, V., Laucou, V., Smets, R., van Onckelen, H., and Schmülling, T. 2003. Cytokinin-deficient transgenic Arabidopsis plants show multiple developmental alterations indicating opposite functions of cytokinins in the regulation of shoot and root meristem activity. Plant Cell 15:2532-2550.

Zimmermann, P., Hirsch-Hoffmann, M., Hennig, L., Gruissem, W. 2004 GENEVESTIGATOR. Arabidopsis microarray database and analysis toolbox. Plant Physiol. 136:2621-2632.

\section{AUTHOR-RECOMMENDED INTERNET RESOURCES}

Affymetrix expression analysis technical manual II: www.affymetrix.com/support/technical/manuals.affx

ArrayExpress, European Bioinformatics Institute: www.ebi.ac.uk/arrayexpress

GabiPD MAPMAN webpage: gabi.rzpd.de/projects/MapMan

John Innes Genome Laboratory: www.jicgenomelab.co.uk

Salk Institute genomic analysis laboratory database SIGnAL: signal.salk.edu/tabout.html

The Arabidopsis Information Resource (TAIR) database: www.arabidopsis.org

The Institute for Genomic Research (TIGR) database: www.tigr.org/tdb/e2k1/ath1/ath1.shtml

\section{Erratum}

A formatting error caused an incorrect column break in the final paragraph of the first column on page 481. The online version was corrected on December 21, 2006. 